\title{
Álvarez de Arenales y el sistema de divisiones durante la Independencia de la Audiencia de Charcas
}

\section{Alvarez de Arenales and the system of divisions during the independence of the Audiencia of Charcas}

Roger L. Mamani Siñani ${ }^{1}$

\section{Resumen}

El artículo analiza la lucha armada en el territorio de la $\mathrm{Au}$ diencia de Charcas durante la guerra de la Independencia con el sistema de divisiones, organización llevada a cabo por Juan Antonio Álvarez de Arenales, quien ordenó y coordinó las acciones de distintos grupos guerrilleros bajo el paraguas que le confería los títulos otorgados por autoridades de las Provincias Unidas del Río de la Plata. Se describe la estructura que se implantó, el funcionamiento, los caudillos y las tropas que formaron parte de esa organización.

Palabras clave: Guerrillas, división militar, sistema de divisiones, insurgentes, guerra de la Independencia

1 Licenciado en Historia por la Universidad Mayor de San Andrés. Investigador de la Coordinadora de Historia. Correspondencia (Corresponding author):Roger_hist@hotmail.com ; Código ORCID: 0000-0003-03811776 


\section{Abstract}

This work analyzes the armed struggle in the territory of the Audiencia de Charcas during the war of Independence with the system of divisions, an organization carried out by Juan Antonio Álvarez de Arenales, who ordered and coordinated the actions of different guerrilla groups under the umbrella conferred by the titles granted by the authorities of the United Provinces of Río de la Plata. It describes the structure that was implemented, the operation, the leaders and the troops that were part of that organization.

Key words: Guerrillas, military division, guerrilla system, insurgents, war of independence

\section{Introducción}

Este artículo busca contraponerse a la visión tradicional de las 'republiquetas', ${ }^{2}$ término que no representa a la organización y función de los grupos armados insurgentes de Charcas. Considero que estos deben ser vistos desde la óptica de la organización militar y la incidencia de ese plano en la organización administrativa. Esas consideraciones ayudan a ver de forma conjunta la actuación de las guerrillas al tomar

2 Véanse, por ejemplo, Bartolomé Mitre, Belgrano y la Independencia Argentina (1887); Luis Paz, Historia de Bolivia, t. II La Independencia (1919); Miguel Ramallo, Guerrilleros de la Independencia: Los esposos Padilla (1919); Alcides Arguedas, Historia general de Bolivia: El proceso de la nacionalidad. 1809-1921 (1922); Luis S. Crespo, Vida y hechos notables del general José Miguel Garcia Lanza y la influencia que ha tenido este héroe en los destinos de Bolivia (1928); Alipio Valencia Vega, El indio en la Independencia (1962); José Macedonio Urquidi, Bolivianas ilustres: Las guerrilleras de la Independencia (1967); Arturo Costa de la Torre, Ildefonso de las Muñecas y los mártires de la republiqueta de Larecaja (1976). 
en cuenta la situación social de los oficiales y de las tropas que conformaban esos cuerpos militares, así como su relación con el comandante en jefe.

El estudio se dividide en cinco partes. En la primera, se analiza la incongruencia de la utilización del término 'republiqueta', pues no corresponde a las características intrínsecas de los grupos armados de Charcas. Esto da paso a la propuesta del término 'división militar', que se acomoda mejor a lo sucedido en la guerra de la Independencia en el Alto Perú. En el segundo acápite, se trata la figura de Juan Antonio Álvarez de Arenales y se muestra la génesis del sistema de divisiones a través de los distintos nombramientos sucedidos en su persona y los hechos fácticos de la aparición de este sistema. En la tercera parte, se aborda la organización del sistema mediante los cargos administrativos y militares que operaban bajo el comando de Álvarez de Arenales. En el cuarto acápite, se trata la conformación social de las tropas y se hace hincapié en sus características. Finalmente, se describe el funcionamiento de la División de los Valles a través de los principales comandantes y su subordinación al comando central de esa organización. ${ }^{3}$

\section{Entre las republiquetas y el sistema de divisiones}

La historiografía ha identificado a Bartolomé Mitre como el autor del término "republiqueta", utilizado para denominar al territorio dominado por un caudillo (1887, p. 561). Esa caracterización fue aceptada por muchos autores bolivianos

3 Este trabajo es un avance de otro mayor dedicado al estudio de la estructura organizacional que Juan Antonio Álvarez de Arenales impuso en tierras charquinas durante la guerra de la Independencia y su comparación con la organización que en tierras peruanas llevó José de San Martín a aquellos lugares. 
sin realizar ninguna reflexión. ${ }^{4}$ De hecho, Luis Paz, copió literalmente la definición de las republiquetas dadas por Mitre (1919, p. 341). Sin embargo, la popularización del término alcanzó otro nivel con Charles Arnade (2004, p. 49), quien en La dramática insurgencia de Bolivia 5 contribuyó a que la 'republiqueta' fuera aceptada definitivamente como la representación de los grupos irregulares que operaron en Charcas durante la guerra de la Independencia. Quizá su mayor aporte al respecto, fue la definición de las siete "republiquetas" que estuvieron presentes en Charcas. ${ }^{6}$ Sin embargo, él vio un mundo insurgente caótico, desordenado, donde un caudillo tenía el dominio de un territorio con características autónomas, que era disputado por otros caudillos, lo que originaría enfrentamientos entre ellos.?

4 Luis Paz (1919), Miguel Ramallo (1919); Alcides Arguedas (1922), y Arturo Costa de la Torre (1976), entre otros pueden identificarse en el grupo de autores que utilizaron la palabra 'republiqueta' sin ninguna reflexión al respecto, pero la dotaron de características heroicas y casi legendarias. Sus obras fueron influyentes y popularizaron el término.

5 El libro fue originalmente publicado como The emergence of the republic of Bolivia en 1957, luego fue traducido al español como La dramática insurgencia de Bolivia en 1959 y ha sido reeditado en diversas ocasiones. La editorial Juventud, encargada de la publicación, ya no colocaba el número de edición en sus últimas versiones, por lo que es difícil saber cuándo dejó de imprimirla. Recientemente, ha aparecido otra copia con el sello de la editorial GUM, que tampoco coloca el número de reedición.

6 Las republiquetas serían la de Larecaja, Ayopaya, Mizque y Vallegrande, Santa Cruz, La Laguna, Cinti y una más de carácter intermitente ubicada en Chayanta (Arnade, 2004, p. 51).

7 En diciembre de 1817 murió el primer comandante en jefe Eusebio Lira, casi inmediatamente reemplazado por Santiago Fajardo. Este duró cerca de tres meses en el cargo hasta que fue reemplazado por José Manuel Chinchilla a raíz de la rebelión de las comunidades indígenas que no aceptaron al nuevo comandante, al cual identificaban como cómplice de la muerte de Lira. Arnade no comprende la complejidad de esas circunstancias, por lo cual atribuye esos cambios a peleas internas entre caudillos. 
Quien terminó por darle a la 'republiqueta' un significado positivo fue José Luis Roca, que vio en esta la génesis del Estado boliviano y colocó su aparición como uno de los hitos fundacionales de lo que es hoy este territorio. ${ }^{8}$ Argumentó que estas eran una especie de estados autónomos, que no aceptaban las intervenciones de porteños ni peruanos, y desconfiaban por igual de los sistemas que ambos representaban. ${ }^{9}$ Por su lado, Raquel Gil Montero (2007, pp. 94, 102) retomó el término, nuevamente sin mucha reflexión, y se centró en el lugar que ocuparon geográficamente y argumentó que aparecieron en territorios de frontera, donde la gente estaba acostumbrada a guerrear en contra de los "indios infieles", por lo cual no se dieron en lugares como el altiplano, que en el momento de la guerra, estaban en calma.

Quizá una de las primeras voces que se alzaron en contra del uso de la palabra republiqueta fue Enrique Finot. Para este autor, el término es inapropiado, pues solo reflejaría una lucha entre pequeños cuerpos políticos provinciales con organización y gobierno propio, lo cual sería inexacto para los cuerpos irregulares de Charcas. En cambio, sí existirían las 'partidas móviles' o grupos armados con bastante movilidad e independencia (Finot, 1930, p.164). De la misma opinión fue Emilio Bidondo. Apoyándose en lo dicho por A. J. Pé-

8 Los hitos anteriores son las antiguas delimitaciones del Kollasuyo y del Antisuyo y la creación de la Audiencia de Charcas, territorios donde se asentaron la Bolivia andina y la amazónico-platense (Roca, 2007, p. 333).

9 En su libro Ni con Lima ni con Buenos Aires (2007) llegó incluso a delimitar las características de la republiqueta de Ayopaya, la cual: "Poseía los elementos básicos de un Estado moderno: territorio, población y gobierno y reconocimiento internacional". Incluso llegó a delimitar la extensión de su territorio en $1.400 \mathrm{~km}^{2}$ (Roca, 2007, p. 242). Con esto, Roca identificó que en Charcas, entre 1814 y 1825, ya existía un Estado autónomo, que sería el antecedente de la República de Bolivia. 
rez Amuchástegui, desechó la idea de 'republiquetas', pues se las concebía como organizaciones de corte republicano o pequeños Estados autónomos soberanos, predominantemente de corte monárquico, con una sede, gobierno, organización administrativa y autoridad central. Para Bidondo, sus relaciones fueron de tipo castrense, subordinados a la autoridad de la Junta de Buenos Aires. El movimiento insurgente que se dio en el Alto Perú fue una guerra de partidarios o guerra de recursos (1989, pp. 144, 475).

Una de las autoras que borra definitivamente de su trabajo la palabra 'republiqueta' para designar a los grupos irregulares de Charcas durante la guerra de la Independencia es Marie-Danielle Demélas (2007). En su concepción, lo que existió en el territorio del Alto Perú durante la guerra de la Independencia fue un sinfín de 'montoneras' o grupos de hombres desorganizados y violentos. ${ }^{10}$ Montonera y guerrilla serían la misma cosa y utiliza ambas palabras de forma indiferente. En Ayopaya, esta situación habría cambiado en 1821 con la llegada de José Miguel Lanza, quien había comenzado a disciplinar a su gente para convertirlos en un verdadero ejército de línea.

Hasta ese momento se concebía al movimiento insurgente como una lucha de montoneros o de guerrilleros desorganizados, los cuales tenían un caudillo que se asentaba en una región específica y que por lo mismo no operaba de forma conjunta con otros caudillos. Contra esta visión, María Luisa Soux plantea la "existencia de un sistema coordinado de los

10 Marie-Danielle Demélas (2007, p. 192) cita un párrafo de la obra Civilización y barbarie de D. F. Sarmiento en 1845, que caracterizaba a las montoneras. El autor, al hablar de Artigas, a quien identificó como el inventor del sistema de la montonera, calificó ese movimiento: “... carácter de ferocidad brutal y ese espíritu terrorista”. Es indudable que Mitre debió haber conocido el libro de Sarmiento e influyó en su definición de montonera y republiqueta. 
grupos guerrilleros" el cual estaría bajo el mando de Juan Antonio Álvarez de Arenales (2007, p. 376).

Los caudillos insurgentes, como los llama, fueron la génesis de la guerra irregular en Charcas. Esos hombres dirigían a sus vecinos, tributarios o familiares con el objetivo de perjudicar a las fuerzas del rey. Luego, fueron organizados por Álvarez de Arenales, quien fue reconocido por los principales jefes guerrilleros como el representante de los altos mandos de Buenos Aires. Por otro lado, muestra que las principales posiciones del ejército del rey estaban en el altiplano central y dominaban las ciudades de La Paz, Oruro, Potosí y Chuquisaca. En cambio, los grupos guerrilleros se habían establecido en las zonas inmediatas a esos territorios, o sea, en los valles y yungas de Charcas, pero de una u otra forma eran marginales. De esa forma, el territorio guerrillero iba desde Larecaja, pasaba por los valles de Sicasica y Ayopaya hacia el territorio de Valle Grande, recalaban en Tomina y la región de Cinti hasta el territorio tarijeño. Ese territorio continuo abrió un canal de comunicaciones importante, que permitió a las fuerzas rioplatenses estar informadas de lo que sucedía con las tropas de Pezuela y con posterioridad con las de La Serna (Soux, 2008, p. 155).

Mitre (1887) dedujo la existencia de ese tipo de organización, pues habló de un "sistema de republiquetas" que operaban aliadas y reconocían la autoridad de Buenos Aires (pp. 561563). Nuevamente, Luis Paz (1919) argumentó la existencia de ese tipo de organización con Muñecas al norte y Camargo al sur (p. 343). Sin embargo, ambos autores no describieron el funcionamiento de ese sistema.

En un trabajo anterior, desarrollé la idea de que el movimiento insurgente localizado en la región de Sicasica y Ayopaya no fue una simple guerrilla ni una montonera. Lo que se vio fue la conformación de una división militar con un mando 
establecido y único que tuvo a Eusebio Lira como su primer comandante en jefe. Esa organización luchaba con la modalidad de la guerra de guerrillas, es decir, con grupos fragmentados que operaban en un amplio espacio territorial y una capacidad de movimiento excepcional, sin buscar un enfrentamiento definitivo, a menos que no se pudiera evitar, pero siempre incomodando al enemigo. Esa división se conformaba principalmente en dos alas, una militar establecida con tropas de infantería, caballería y artillería, y otra ala conformada por los comandantes locales, que eran caudillos con su propia gente, la mayoría de origen indígena, ${ }^{11}$ que actuaban con más independencia, pero respondían a las órdenes de Lira. Esa división se consideraba parte integrante de las tropas auxiliares a cuyos jefes le debían el máximo respeto y subordinación (Mamani Siñani, 2010).

Si tomamos en cuenta la propuesta de María Luisa Soux y la mía podemos entender mejor el fenómeno insurgente que ocurrió en Charcas durante la guerra de la Independencia. Es decir, en esa región se registró la existencia de grupos armados bajo el comando general de Juan Antonio Álvarez de Arenales con la modalidad de divisiones militares esparcidas en un amplio territorio que controlaban los valles y yungas de Charcas.

Con esta concepción, podemos entender que los distintos caudillos detentaron o procuraban obtener grados militares,

11 El estudio de la participación indígena en el proceso de la Independencia de Bolivia se ha retomado a partir de los trabajos de Demélas (2007) para el caso de la guerrilla de Ayopaya; de Soux (2010) en torno a los caudillos indígenas de Oruro y de Mamani (2010) sobre la participación indígena en las fuerzas de la División de los Valles de La Paz y Cochabamba. En el Perú, con una óptica distinta, están los trabajos de Husson (1992) y Méndez (2014) para el caso del ejército iquichano, que se enfrentó al Estado peruano en defensa del rey y la religión. 
que eran reconocidos o proporcionados por los altos mandos de los ejércitos auxiliares enviados desde las Provincias Unidas del Río de la Plata. De esa forma, su autoridad se basaba en la legitimidad que les daba el grado militar. La táctica de lucha fue la guerra de guerrillas, aunque como una división militar en forma y en fondo; muchas veces buscaron enfrentamientos abiertos, como en el caso de la batalla de la Florida. Sin embargo, esa organización tuvo sus particularidades sin las cuales no se podría entender la amplitud del mismo.

\section{Rasgos de la actuación de Juan Antonio Álvarez de Are- nales $^{12}$ en Charcas}

Manuel Belgrano al mando del Segundo Ejército Auxiliar del Alto Perú ingresó a la Villa de Potosí el 21 de junio de 1813. Desde ese punto, este general realizó importantes acciones con miras a la organización de las provincias interiores. Una de sus decisiones más trascendentales, que repercutió en el movimiento de la guerra, fue nombrar a Juan Antonio Álvarez de Arenales como gobernador político y militar de la provincia de Cochabamba y todas sus dependencias el 6 de septiembre de 1813 (AGNA, sala VII, leg. 2561, caja 6, doc. 226).

Lo resaltante es que Belgrano oficialmente no lo nombró gobernador intendente, como se ha señalado en diversas ocasiones, sino gobernador militar y político y como tal lo aceptó

12 Para la gestión de Juan Antonio Álvarez de Arenales en Salta después de su paso por el Perú y el ejército de los Andes, consultar Dipasquale (2009). Un interesante estudio sobre la conformación de tropas basada en el clientelismo y paternalismo entre los pequeños hacendados y grandes propietarios de Salta, que se desarrolló al mismo tiempo que Álvarez de Arenales organizaba el sistema de divisiones, se encuentra en Mata (2000, pp. 149-175). 
el cabildo cochabambino. Sin embargo, Álvarez de Arenales objetó esa decisión y pidió a Belgrano que:

... en circunstancias tan próximas a otra acción deje seguir al Ejército, y hallarse en ella, por ir a servir en otro empleo de menos riesgo, y mejor comodidad. Suplica a V.E. que siendo servido y si hubiere otro sujeto aparente para el indicado destino, le permita al representante lograr la gloria de militar en las banderas de la patria, o en caso contrario tener presentes estos sus deseos en abono de su honor... (AGNA, sala VII, leg. 2566, doc. 628)

Esos empleos suponían hacerse cargo de la administración burocrática de la provincia a su mando. Es por eso que Álvarez de Arenales declinó el nombramiento, pues quería seguir en el cuerpo del ejército como militar de carrera. Sin embargo, Belgrano le contestó que "Los servicios a la Patria son de igual mérito en las armas, como en lo político y civil... no ha lugar a la solicitud que hace y siga su destino". En ese oficio de respuesta se hace mención al cargo de gobernador intendente y es con esa denominación que ordena a "todos los maestros de postas, vecinos y jueces de tránsito" le auxilien en todo lo que pudiesen en su camino hacia Cochabamba (AGNA, sala VII, leg. 2566, doc. 628).

Ese nombramiento le fue confirmado a Álvarez de Arenales por las autoridades de Buenos Aires el 1 de octubre de 1813, es decir, menos de un mes después del firmado por Belgrano. Con la nominación de gobernador intendente, también vino la "instrucción reservada" para el gobierno de esa región. Su jurisdicción fue el "Distrito de Cochabamba y pueblos de su inmediata dependencia, con separación de Santa Cruz de la Sierra y las dependencias de esta" (AGNA, sala VII, leg. 2566, doc. 628), pues quedaban en la jurisdicción de Ignacio Warnes, quien también fue nombrado gobernador de esa zona. 
La "instrucción reservada" es un documento extenso ${ }^{13}$ y ante todo son órdenes para que se administre la provincia; muy poco se refiere al tema militar. Por ejemplo, se le manifiesta que: “... trate de formar una descripción estadística de toda la provincia" con el objetivo de saber la "... población de cada feligresía con expresiones de las clases, estado, edades y sexos..." (AGNA, sala VII, leg. 2566, doc. 628). Quizá eso haya ocurrido por la presencia del coronel Cornelio Zelaya en Cochabamba, quien fue comisionado por Belgrano para organizar una división de caballería que debía apoyar al ejército auxiliar (Paz, 1919). En la instrucción se lee que mientras el mismo esté en este territorio, él: “... tendrá el mando de las armas, pero luego que salga con ella con la División titulada de Cochabamba quedan las cosas en el mismo orden que antes de darle dicha comisión al expresado coronel Zelaya”" (AGNA, sala VII, leg. 2566, doc. 628). Es decir, que Álvarez de Arenales se quedaba al mando de la provincia en lo militar y político-civil.

Muy poco tiempo se quedó Arenales en Cochabamba, pues se retiró de ella el 29 de noviembre de 1813, poco después de la derrota de Belgrano en Ayohuma (14 de noviembre). Argumentó para su salida que si se quedaba y hubiera tenido un enfrentamiento con el enemigo habría "causado su total ruina”. Con la poca gente que le siguió, se refugió en Vallegrande (actualmente ubicada en el departamento de Santa Cruz) y desde allí comenzó a organizar sus tropas. Inicialmente, estas se conformaron con poco menos de 200 hombres, que compusieron la división de Cochabamba (Quispe, 2018, p. 19).

13 Se desconoce exactamente cuántas fojas ocupó las órdenes de Belgrano contenidas en ese documento, pues lo que se tiene en el Archivo de Juan Antonio Álvarez de Arenales son las transcripciones en máquina de escribir de J. E. Uriburo y no tienen un indicio de su extensión. 
En los hechos, después de la retirada de Belgrano en noviembre de $1813,{ }^{14}$ Arenales se quedó al mando de lo militar y de lo civil, pues era la máxima autoridad designada que se había quedado. El personaje que hubiera competido con él por el mando supremo fue Ignacio Warnes, quien fue nombrado gobernador de Santa Cruz. Sin embargo, en el esquema dado por la instrucción de intendentes para el virreinato del Río de La Plata, Santa Cruz se consideraba como un territorio de frontera, por lo cual si se juzgaba conveniente se separaba el mando en dos y el gobernador quedaba con el mando militar y el intendente con el mando político y económico. ${ }^{15}$ En ese caso, operó ese modelo y Warnes se convirtió en el jefe superior militar de Santa Cruz, pero como Álvarez de Arenales era gobernador político y militar, es decir, con más facultades que el primero, fue la máxima autoridad reconocida por todos, incluido Warnes, aunque siempre mostró rebeldía ante esa autoridad. ${ }^{16}$

14 Una de las acciones de Belgrano en suelo charquino fue nombrar autoridades, como gobernadores o subdelegados. Una vez que este salió del territorio altoperuano, estas asumieron el cargo de las operaciones militares, uno de ellos fue Juan Antonio Álvarez de Arenales, nombrado gobernador de Cochabamba (Quispe, 2018). Otra de las consecuencias de la presencia de Belgrano fue la aparición de caudillos que lucharon con el formato de la guerra de guerrillas. Canedo Gutiérrez (2016) ha identificado 40 nombres que encabezaron tropas irregulares que pelearon entre las intendencias de Chuquisaca y Potosí. En la región de Ayopaya, hubo 42 caudillos que aparecieron antes y después de la salida del segundo Ejército de Operaciones Auxiliares (Mamani Siñani, 2010). Esto muestra que si bien la derrota fue un duro golpe, no significó que la guerra hubiera terminado, por el contrario, fue sostenida por grupos guerrilleros, algunos de gran importancia. Al principio, estos actuaron sin coordinación alguna, pero con el tiempo fueron puestos bajo la dirección de Álvarez de Arenales, lo cual es objeto de este trabajo.

15 Real Ordenanza para el Establecimiento e Instrucción de Intendentes del Ejército y Provincia para el Virreinato de Buenos Aires, Art. 6.

16 Sobre la relación entre Juan Antonio Álvarez de Arenales e Ignacio Warnes 
Al principio, Álvarez de Arenales operó en el territorio de su jurisdicción, es decir, Cochabamba, pero con el paso del tiempo logró la lealtad de caudillos más allá de esas fronteras, así, Manuel Ascencio Padilla en Tomina y Vicente Camargo en Cinti se pusieron bajo sus órdenes. Por otro lado, se encargó de abrir comunicaciones con Juan Manuel Pinelo y Torre que venía con tropas del Cuzco, al norte de su territorio (Soux, 2018), lo que veremos con más detalle.

Sin embargo, lo que terminó por afianzar su mandato fueron dos documentos enviados directamente por las máximas autoridades del sur. El primero es el nombramiento de "Gobernador Intendente de la Provincia de Cochabamba" por parte de Gervasio Antonio Posadas, supremo director del Estado de las Provincias Unidas del Río de la Plata, fechado en Buenos Aires el 19 de octubre de 1814 (AGNA, sala VII, leg. 2561, doc. 229). El segundo, es el Oficio N. ${ }^{\circ} 61$ de José de Rondeaú, fechado en Jujuy el 30 de octubre de 1814, en el que le nombra "Comandante General de las Tropas del Interior" (Biblioteca de Mayo. Colección de Obras y Documentos para la Historia Argentina, t. XV, p. 13379). Ambos documentos tienen fecha cercana y son consecuencia de la victoria de la batalla de la Florida, que sucedió el 25 de mayo del año mencionado, pero cuyas noticias se conocieron de manera oficial por aquellos días.

El nombramiento de "Comandante General de las Tropas del Interior" colocó a Juan Antonio Álvarez de Arenales, de

siempre ha habido coincidencias al resaltar lo mal que se llevaban y el carácter rebelde que tendía hacia la autonomía del último (Paz, 1919; Arguedas, 1922; Roca, 2007). Sin embargo, Gandarilla Guardia (2017) considera que Warnes siempre fue el vilipendiado e incluso que la victoria de La Florida se debió a la actuación de este y que Álvarez de Arenales le robó el triunfo al informar primero a los mandos superiores de Buenos Aires y colocarse él como el gran vencedor (pp. 61, 72, 73). 
manera oficial, como el máximo jefe militar en Charcas ante la ausencia del general del ejército auxiliar. Las partes más importantes de ese oficio dicen lo siguiente:

El mejor servicio del Estado y el grande objeto de reintegrar prontamente el territorio de las Provincias Unidas del Río de la Plata libertándolas de la dominación de las armas agresoras del virrey de Lima... exigen imperiosamente la interesante medida de concentrar, sin pérdida de tiempo el comando general de todas las tropas, y reuniones de patriotas armados que operan en diferentes puntos del interior defensiva $u$ ofensivamente contra el común enemigo, en la persona de un jefe de carácter que reuniendo las recomendables calidades de patriotismo acreditado, honradez actividad y conocimientos militares, se haya digno de la confianza pública, de la mía y del supremo gobierno...

A tal importante fin, concurriendo aquellas calidades en la recomendable persona de vuestra señoría he dispuesto, que desde el partido de Cinti, exclusive (quedando este y el de Tarija sujetos por ahora al mando militar del comandante general de avanzadas coronel don Martín Güemes) todas las demás fuerzas de las provincias y partidos del interior que en el día se hallen libres, o en adelante vayan libertándose de la opresión del enemigo, hasta la provincia de La Paz, se pongan inmediatamente y queden desde luego sujetas al comando general de Vuestra Señoría para que arreglándose a las instrucciones que le tengo comunicadas opere en combinación con este ejército de mi mando del modo más conveniente a la interesante y pronta ejecución de aquellos grandes objetos. [negritas ańadidas]

Con esa instrucción, el coronel Juan Antonio Álvarez de Arenales quedaba en libertad de someter a su comando a cualquier tropa insurgente, ya sea esta grande como la de Juan Manuel Pinelo en La Paz, o una insignificante "reunión de patriotas" como aquellas que operaban en las breñas de los valles de Sicasica y Ayopaya; todas debían prestarle obediencia. Sin duda, ese es el documento que formaliza la existencia de un sistema coordinado de guerrillas a la cabeza de Álvarez 
de Arenales. La intención de los superiores de Buenos Aires fue preparar el camino del tercer ejército auxiliar, para lo cual necesitaban un comando unificado con el cual comunicarse y que este a su vez transmita sus órdenes.

Es interesante observar la jurisdicción de su comando, que abarcaba desde Cinti hasta La Paz, es decir, el territorio de guerrillas surgido poco después de la retirada del primer ejército auxiliar al mando de Antonio Gonzales Balcarce y Juan José Castelli, pero que se afianzó después de la salida de Belgrano del territorio charquino. Tarija quedaba fuera de su territorio, el cual estaba encomendado a las avanzadas de Martín Miguel de Güemes. Esto se debe a que esa región pasó a depender, a principios de siglo XIX, de la Gobernación e Intendencia de Salta, por lo cual no se la consideraba parte del Alto Perú.

Considero que esa división territorial tuvo una marcada importancia, pues el territorio de dominio de Güemes actuaba como una especie de frontera-escudo contra las avanzadas de las tropas del rey. Por eso, los comandantes del territorio de Tarija no se reportaban a Álvarez de Arenales como sucedía con los que estaban en Charcas, sino con Güemes. Un claro ejemplo es el teniente coronel Manuel Uriondo, quien luego de la batalla de La Tablada, envió partes del suceso al comandante salteño (Sánchez Cari, 2018, p. 141).

Ante el prestigio que las tropas de Álvarez de Arenales habían alcanzado, este fue nombrado coronel del Regimiento de Infantería N. ${ }^{\circ} 12$, es decir, sus huestes pasaron de ser una división guerrillera a una fuerza de línea. Con ese rango, llegó a engrosar las fuerzas de Rondeaú que se encontraban en Chayanta en octubre de 1815 (Biblioteca de Mayo. Colección de Obras y Documentos para la Historia Argentina, t. XV, p. 13439). Ese nombramiento se hizo efectivo el 1 de diciembre del año mencionado por parte del Director Provisional de las 
Provincias Unidas del Río de La Plata (AGNA, sala VII, leg. 2566, doc. 628).

Con ese título se retiró de suelo charquino, pues luego de la batalla de Sipesipe, el 29 de noviembre de 1815, donde las fuerzas de Rondeaú fueron derrotadas por las de Pezuela, Juan Antonio Álvarez de Arenales salió de la escena de la lucha insurgente en suelo altoperuano. Sin embargo, reapareció en 1821 acompañando a José de San Martín en su campaña por la sierra peruana.

\section{Organización del sistema de divisiones.}

Retornando a la instrucción reservada dada por Manuel Belgrano a Juan Antonio Álvarez de Arenales, ese documento en una de sus partes decía: “... les dará a los más honrados y pudientes, algunas comisiones" (AGNA, sala VII, leg. 2566, doc. 628). Ese hecho posibilitó nombrar a gente que consideraba importante con cargos civiles o militares. Eso se comprueba, por ejemplo, con los casos de José Buenaventura Zárate y Santiago Fajardo. El primero fue hijo del marqués de Montemira y el segundo era un rico propietario de minas en Yani y hacendado local (Demélas, 2007, pp. 43, 253). Ambos fueron contactados por Álvarez de Arenales, quien nombró como subdelegado de Sicasica a Zárate y como comandante de Guallipaya a Fajardo (AGNA, sala VII, leg. 2565, doc. 437).

80 En el archivo del general Juan Antonio Álvarez de Arenales se conservan numerosas cartas dirigidas al gobernador intendente de Cochabamba, firmadas por autoridades políticas menores, como subdelegados y alcaldes. Se tiene constancia de que, en una primera instancia, esos cargos fueron designados por el mismo Belgrano, pero una vez que este salió del suelo charquino, Álvarez de Arenales debió de tomar esa responsabilidad. En ese sentido, la guerra de la Independen- 
cia nos plantea otro ángulo muy poco estudiado, el de las autoridades locales y la administración que estas impartieron en tiempos de guerra. Esa administración no chocaba con sus labores militares, en especial de los subdelegados, quienes actuaron como los comandantes militares de su región, actuaron a la cabeza de sus tropas y protagonizaron enfrentamientos y batallas.

\section{Cuadro 1. Listado de personajes con cargos administrativos}

\begin{tabular}{|l|l|l|l|}
\hline \multicolumn{4}{|c|}{ Listado de personajes con cargos administrativos } \\
\hline $\begin{array}{l}\text { Fecha del } \\
\text { documento }\end{array}$ & Nombre & Cargo & Lugar \\
\hline 20/09/1813 & José Benito Tapia & Subdelegado & Arque \\
\hline $07 / 07 / 1815$ & Julián Manzana & Subdelegado & Arque \\
\hline $07 / 07 / 1815$ & José Benito Antezana & Subdelegado & Arque \\
\hline 20/09/1813 & N. Saavedra & Subdelegado & Tapacarí \\
\hline $07 / 07 / 1815$ & Pedro Ustariz & Subdelegado & Tapacari \\
\hline 20/09/1813 & Josef Gonzales & Subdelegado & Cliza \\
\hline 20/09/1813 & Francisco Paula Quiroga & Subdelegado & Ayopaya \\
\hline $07 / 07 / 1815$ & Ilarión Flores & Subdelegado & Ayopaya \\
\hline 20/09/1813 & Toribio Cardozo & Subdelegado & Sacaba \\
\hline $07 / 07 / 1815$ & José Benito Canclas & Subdelegado & Sacaba \\
\hline $20 / 09 / 1813$ & Miguel Vela & Subdelegado & Mizque \\
\hline $07 / 07 / 1815$ & José Benito Tapia & Subdelegado & Mizque \\
\hline $07 / 07 / 1815$ & Manuel Blacut & Subdelegado & Mizque \\
\hline $05 / 04 / 1814$ & Pedro de Ustariz & Subdelegado & Valle Grande \\
\hline $07 / 07 / 1815$ & José Manuel Balderrama & Subdelegado & Valle Grande \\
\hline $03 / 11 / 1814$ & Miguel Zapata & Alcalde Preventivo & Chimboata \\
\hline $11 / 1814$ & Andrés Vela & Alcalde & Totora \\
\hline $11 / 1814$ & Gregorio Román & Comisionado & Chilon \\
\hline $11 / 1814$ & Cap. Mateo Terrazas & Alcalde & Durazno \\
\hline
\end{tabular}




\begin{tabular}{|l|l|l|l|}
\hline \multicolumn{4}{|c|}{ Listado de personajes con cargos administrativos } \\
\hline $\begin{array}{l}\text { Fecha del } \\
\text { documento }\end{array}$ & Nombre & Cargo & Lugar \\
\hline $11 / 1814$ & Casimiro Herbas & Alcalde & Pocona \\
\hline $02 / 01 / 1815$ & Francisco del Carpio & Gobernador Provisional & Totora \\
\hline 09/02/1815 & Manuel Aguilar & Alcalde & Chalguani \\
\hline $11 / 02 / 1815$ & Dionisio Palenque & Subdelegado & [Río del Pescado] \\
\hline $12 / 02 / 1815$ & Manuel José de Aguado & Alcalde & Chilon \\
\hline 19/06/1815 & Manuel Ascencio Padilla & Subdelegado Militar & Tomina \\
\hline $02 / 10 / 1815$ & Vicente Camargo & Subdelegado & Chayanta \\
\hline $07 / 07 / 1815$ & José Bentura Zárate & Subdelegado & Sicasica \\
\hline 28/11/1815 & Francisco del Carpio & Subdelegado & Sicasica \\
\hline
\end{tabular}

Fuente: Elaboración propia basado en AGNA, Colección Juan Antonio Álvarez de Arenales, Biblioteca Mayo y Ramallo, 1975.

El cuadro es una pequeña muestra de la amplitud del sistema gubernativo que se manejó cuando Juan Antonio Álvarez de Arenales estuvo como gobernador militar y político de Cochabamba. Para entender mejor la información, debemos tener en cuenta algunas fechas.

El nombramiento de Juan Antonio Álvarez de Arenales como gobernador político y militar se hizo el 15 de septiembre de 1813. La retirada del segundo ejército auxiliar se efectuó en noviembre de ese año. Su nombramiento como comandante general de las tropas del interior fue fechada el 30 de octubre de 1814. La llegada del tercer ejército auxiliar se verificó en abril de 1815 . Finalmente, la retirada de ese ejército de tierras charquinas fue en noviembre de 1815 . Como se puede verificar, entre la salida de Manuel Belgrano y la llegada de José de Rondeaú habían pasado 18 meses; es lógico pensar que en ese tiempo Juan Antonio Álvarez de Arenales tuvo que hacerse cargo de todas las operaciones de la insurgencia, pues fue el jefe con la más alta graduación, 
además de tener el cargo más relevante que quedó en tierras altoperuanas.

Durante su estancia en Charcas, Belgrano nombró a seis subdelegados, todos de la provincia de Cochabamba, estos fueron N. Saavedra, Francisco Paula Quiroga, Toribio Cardozo, Miguel Vela, José Benito Tapia y Josef Gonzales (AGNA, sala VII, leg. 2566, doc. 628). Poco sabemos de los antecedentes de esos personajes, Belgrano menciona que Saavedra "... fue comandante de Sipesipe y emigró a Tucumán”, pero nada más. Por otro lado, los tres últimos siguieron en sus puestos después de la retirada del segundo ejército auxiliar y como consecuencia, estuvieron bajo las órdenes de Juan Antonio Álvarez de Arenales.

Por ahora, solo puedo suponer la suerte de los otros tres personajes. Al encontrarse muy pocas referencias de estos, presumo que salieron hacia las Provincias Unidas después de la derrota de Belgrano en Vilcapujio, que murieron en acción o desaparecieron sin dejar rastro. En consecuencia, el gobernador de Cochabamba tuvo que nombrar a otros para cubrir los puestos acéfalos.

En julio de 1815, Álvarez de Arenales reportó que en el caso de Ayopaya: “... el subdelegado nombrado antes se ha perdido...", por lo cual nombró a Ilarión Flores en su reemplazo (AGNA, sala VII, leg. 2565, doc. 429). El subdelegado puesto por Belgrano en esa región fue Francisco Paula Quiroga, quien habría desaparecido. Algo similar debió ocurrir con Toribio Cardozo, subdelegado de Sacaba, nombrado en ese puesto por el general del ejército auxiliar y fue reemplazado por José Benito Canclas.

En Arque, Álvarez de Arenales, reportó que su subdelegado era Julián Manzana, pero que: “... se vino a presentar a los enemigos contra mí...” por lo cual fue reemplazado por 
José Benito Antezana “... mozo apto de acreditada adhesión a nuestra causa...” (AGNA, sala VII, leg. 2565, doc. 429). Originalmente, fue nombrado como subdelegado de esa región José Benito Tapia. Sin embargo, en julio de 1815 fue mencionado como el anterior subdelegado de Mizque, pero fue reemplazado por Manuel Blacut, en razón de que "... no ha querido apersonarse en él, cuando con grabe necesidad exigía juez, prefiriendo las atenciones de granjerías y otras ocupaciones de propio egoísmo..." (AGNA, sala VII, leg. 2565, doc. 429).

Al parecer, esos cambios sucedían de forma común, quizá por la conveniencia de los nombrados al tener algún interés en las regiones de sus destinos. Eso parece mostrar el caso de los subdelegados Pedro Ustariz de Vallegrande y José Manuel Balderrama de Tapacarí, quienes “... en conformidad de mutuo consentimiento..." optaron por cambiar de destinos el uno con el otro (AGNA, sala VII, leg. 2565, doc. 429).

El último caso de reemplazo que he identificado es el de José Bentura Zárate, quien fue nombrado por Álvarez de Arenales como subdelegado de Sicasica. Sin embargo, en noviembre de 1815, en ese mismo puesto se ha identificado a Francisco Carpio. Este, actuó primero como comandante de vanguardia en Totora y luego, cuando se tuvo noticias ciertas de que el tercer ejército auxiliar estaba en camino, se desempeñó como "Capitán de Ejército, Subdelegado del Partido de Sicasica y Comandante en Jefe de Vanguardia por comisión del

84 Sr. Gobernador Intendente y Comandante General de esta Provincia, Juan Antonio Álvarez de Arenales" (AGNA, sala VII, leg. 2569, doc. 1251).

Por otro lado, tenemos la presencia de seis alcaldes o alcaldes preventivos incluidos en la Real Ordenanza para el Establecimiento e Instrucción de Intendentes de Ejército y Provincia para el Virreinato De Buenos Aires (Art. 8, pp. 30-35) pro- 
mulgada en 1782, que hace referencia a los alcaldes ordinarios, quienes conformaban el ayuntamiento de cada "ciudad, villa o lugar de españoles" y tenían la facultad de ocuparse de la administración y manejo de esas localidades en lo económico, su abastecimiento, el buen orden de la villa o ciudad, etc.

La presencia del alcalde también se registra en la Constitución Política de la Monarquía Española promulgada en Cádiz en 1812. Es muy probable que los personajes que aparecen con esos cargos hayan tenido las atribuciones que el citado documento les daba, entre ellos, constituirse en una especie de primer juez con residencia en los pueblos, quien tenía las atribuciones de conciliador de causa civiles y de injurias. ${ }^{17}$

Por otro lado, a semejanza de las atribuciones dadas por la Real Ordenanza de Intendentes, los alcaldes eran los que presidían los ayuntamientos de los pueblos ante la falta de jefe político. ${ }^{18}$ A la vez, los ayuntamientos se encargaban de la

17 La Constitución de Cádiz señala: Art. 275. En todos los pueblos se establecerán alcaldes, y las leyes determinarán la extensión de sus facultades, así en lo contencioso como en lo económico. Art. 283. El alcalde, con dos hombres buenos, nombrados uno por cada parte, oirá al demandante y al demandado, se enterará de las razones en que respectivamente apoyen su intención, y tomará oído el dictamen de los dos asociados, la providencia que le parezca propia para el fin de terminar el litigio sin más progreso, como se terminará, en efecto, si las partes se aquietan con esta decisión extrajudicial.

18 La Constitución de Cádiz señala: Art. 46. Las juntas de parroquia serán presididas por el jefe político, o el alcalde de la ciudad, villa o aldea en que se congregaren, con asistencia del cura párroco para mayor solemnidad del acto; y si en un mismo pueblo, por razón del número de sus parroquias, se tuvieren dos o más juntas, presidirá una el jefe político, o el alcalde, otra el otro alcalde, y los regidores, por suerte, presidirán las demás. Art. 67. Las juntas electorales de partido serán presididas por el jefe político, o el alcalde primero del pueblo cabeza de partido, a quien se presentarán los electores parroquiales con el documento que acredite su 
salubridad, el orden público la administración de recursos económicos del pueblo, la apertura de caminos, la construcción de puentes, etc. ${ }^{19}$

La presencia de estos alcaldes o alcaldes preventivos nos indica que Juan Antonio Álvarez de Arenales, así como los subdelegados de cada partido, a los que ya hice referencia, tenían mayor interés en la administración de las localidades. Esto no se habría podido llegar a hacer sin que en ellas no se hubiese tenido pleno control del espacio territorial, sobre todo teniendo en cuenta el tiempo de guerra en el que se vivía.

Con esto quiero decir que el control del espacio territorial mediante la presencia de esos alcaldes y subdelegados aseguraba el suministro de dinero, alimentos y vestidos para la

elección, para que sean anotados sus nombres en el libro en que han de extenderse las actas de la junta.

19 La Constitución de Cádiz señala: Art. 321. Estará a cargo de los Ayuntamientos: Primero. La policía de salubridad y comodidad. Segundo. Auxiliar al alcalde en todo lo que pertenezca a la seguridad de las personas y bienes de los vecinos, y a la conservación del orden público. Tercero. La administración e inversión de los caudales de propios y arbitrios, conforme a las leyes y reglamentos, con el cargo de nombrar depositario bajo responsabilidad de los que le nombran. Cuarto. Hacer el repartimiento y recaudación de las contribuciones, y remitirlas a la Tesorería respectiva. Quinto. Cuidar de todas las escuelas de primeras letras y de los demás establecimientos de educación que se paguen de los fondos del común. Sexto. Cuidar de los hospitales, hospicios, casas de expósitos y demás establecimientos de beneficencia, bajo las reglas que se prescriban. Séptimo. Cuidar de la construcción y reparación de los caminos, calzadas, puentes y cárceles, de los montes y plantíos del común, y de todas las obras públicas de necesidad, utilidad y ornato. Octavo. Formar las Ordenanzas municipales del pueblo y presentarlas a las Cortes para su aprobación por medio de la Diputación provincial, que las acompañará con su informe. Noveno. Promover la agricultura, la industria y el comercio, según la localidad y circunstancias de los pueblos, y cuanto les sea útil y beneficioso. 
tropa militar, además de bastimentos militares, como la pólvora para las armas de fuego, "fierros", que se utilizaban para el mantenimiento de los fusiles y para hacer armas blancas y otros elementos sin los cuales la subsistencia de los guerrilleros no estaba asegurada. No en vano, en el archivo de Juan Antonio Álvarez de Arenales hay un "cuaderno de cargo y data de las partidas que salen y entran a mi poder, resultivas de mi comisión” (AGNA Sala VII Leg 2567 Doc. 836), que le fue remitido por Francisco del Carpio.

La sobreposición de cargos entre subdelegados y alcaldes entre el "partido del rey" y el de "la patria" hacía que los hombres designados para esas tareas tuvieran en cuenta para su aceptación el lugar donde estaban, si eran dominios de los insurgentes o de los realistas. Un caso particular fue el de Manuel de Aguilar, quien recibió el nombramiento de Alcalde Preventivo de Chalguani, pero por parte de las tropas del rey en la persona del comandante Pedro José de Ugarte el 4 de febrero de 1815 . Ese nombramiento fue remitido a Francisco del Carpio con una carta personal de la designada autoridad el 9 de febrero de 1815, en la que negaba la misma y pedía socorro ante los estragos de los del rey: “... por Dios señor mío no permitan ustedes peligre tanta gente el nombramiento que me hacen no acabo de saber con qué fin querrán ponerme de alcalde ni Dios permita estando ustedes vivos querrán matarme pues estoy en estos montes de Tarucani..." (AGNA, sala VII, leg 2567, doc. 804).

Se nota en la carta que Aguilar les temía a los insurgentes, ¿Cómo se puede entender esa situación? La zona en cuestión era de dominio de Francisco del Carpio, se podría decir que Chalguani era un punto de entrada hacia Valle Grande, por lo cual la presencia de las tropas insurgentes era constante. Por otro, las fuerzas del rey se componían de tropas "pacificadoras" que entraban en una determinada fecha, no eran del lugar y cuando se acababa su misión se retiraban, es decir, no 
permanecían mucho tiempo. El control y dominio del territorio era insurgente, por lo cual colocarse del lado realista era muy peligroso.

Además de esos personajes con cargos político-administrativos, había los que ocuparon un puesto ante todo militar como comandantes o capitanes en determinadas regiones. El siguiente cuadro es una muestra de esa situación, pero considero que aún no está completa.

\section{Cuadro 2. Listado de personajes con cargos militares}

\begin{tabular}{|l|l|l|l|}
\hline \multicolumn{5}{|c|}{ Listado de personajes con cargos militares } \\
\hline $\begin{array}{l}\text { Fecha del } \\
\text { documento }\end{array}$ & Nombre & Cargo & Lugar \\
\hline $02 / 1814$ & Justo Pastor Alfonso Medina & $\begin{array}{l}\text { Capitán Coman- } \\
\text { dante }\end{array}$ & Dunas \\
\hline 16/03/1814 & José Manuel Zurita & $\begin{array}{l}\text { Capitán Comandan- } \\
\text { te Vanguardia }\end{array}$ & Valle Grande \\
\hline 01/04/1814 & Diego de la Riva & Comandante & $\begin{array}{l}\text { Cuartel en } \\
\text { Cabezas }\end{array}$ \\
\hline 08/04/1814 & Francisco Guzmán & Comandante & Palcaloma \\
\hline 09/04/1814 & Apolinar Arenales & $\begin{array}{l}\text { Comandante de } \\
\text { avanzadas [Ayudante } \\
\text { Mayor] }\end{array}$ & $\begin{array}{l}\text { Avanzadas de } \\
\text { San Pedro }\end{array}$ \\
\hline 18/04/1814 & Theodoro Terrazas & Capitán & Totora \\
\hline 10/06/1814 & José Mateo Berdeja & Comandante & San José \\
\hline 10/071814 & José Ignacio Zárate & Comandante en Jefe & Pomabamba \\
\hline 16/08/1814 & Jorge Michel & $\begin{array}{l}\text { Capitán Comandan- } \\
\text { te de Pomabamba }\end{array}$ & Pomabamba \\
\hline $31 / 08 / 1814$ & Antonio Gallardo & Capitán & Cocha \\
\hline $04 / 11 / 1814$ & José Serna & Mayor & Totora \\
\hline $09 / 11 / 1814$ & Francisco del Carpio & $\begin{array}{l}\text { Comandante de } \\
\text { Vanguardia }\end{array}$ & Totora \\
\hline
\end{tabular}




\begin{tabular}{|l|l|l|l|}
\hline \multicolumn{5}{|c|}{ Listado de personajes con cargos militares } \\
\hline $\begin{array}{l}\text { Fecha del } \\
\text { documento }\end{array}$ & Nombre & Cargo & Lugar \\
\hline 22/11/1814 & Mathias Artieda y Solís & Capitán de la Patria & $\begin{array}{l}\text { Estancia de } \\
\text { Sincuisiri }\end{array}$ \\
\hline 25/11/1814 & José Manuel Alva & $\begin{array}{l}\text { Teniente Coronel y } \\
\text { Comandante en Jefe }\end{array}$ & $\begin{array}{l}\text { Cuartel General } \\
\text { de Mizque }\end{array}$ \\
\hline 18/01/1815 & José Bentura Zarate & Comandante & Guallipaya \\
\hline 28/01/1815 & José Manuel de Arana & Comandante & Capinata \\
\hline 29/01/1815 & José Aceituno & Capitán & Aiquile \\
\hline $02 / 02 / 1815$ & Vicente Camargo & $\begin{array}{l}\text { Comandante de } \\
\text { Provincia }\end{array}$ & Cinti \\
\hline $03 / 02 / 1815$ & Santiago Fajardo & Comandante & $\begin{array}{l}\text { Cordillera de } \\
\text { Laxia }\end{array}$ \\
\hline 11/02/1815 & Fray Bernardo Mariano & Cura/Capitán & Río del Pescado \\
\hline 25/02/1815 & Manuel Rojas & Capitán & Poxo \\
\hline 28/02/1815 & Manuel Castellón & Capitán & Poxo \\
\hline $01 / 03 / 1815$ & Ilario Rodríguez & Capitán & Pescado \\
\hline $06 / 03 / 1815$ & José Manuel de Arana & Comandante & Palca \\
\hline 28/12/[1815] & Melchor Castro & Capitán & Tomina \\
\hline
\end{tabular}

Fuente: Elaboración propia basado en AGNA, Colección Juan Antonio Álvarez de Arenales.

Todos los capitanes o comandantes se reportaban primero ante su inmediato superior, en este caso, el comandante de provincia o el subdelegado del partido, luego estos remitían sus informes en forma resumida o adjunta a Juan Antonio Álvarez de Arenales como comandante en jefe. Un ejemplo es el caso de Antonio Gallardo, comandante de Cocha en Cinti, quien primero se reportó a Vicente Camargo y luego este retransmitió el mensaje en una carta fechada el 31 de agosto de 1814 (AGNA, sala VII, leg. 2567, doc. 726). 
Los nombramientos de comandantes se hacían oficiales con la venia de Juan Antonio Álvarez de Arenales. En una carta del 31 de agosto de 1814, transcrita por Vicente Camargo, enviada por José Ignacio Zárate y luego remitida al gobernador intendente, el segundo le ordena al primero que marche al punto de Agchilla o Mollepinto:

...con la poca o mucha gente que voluntariamente le acompañe esto lo verificara Vuestra Merced sin excusa ni réplica [pues esta precisado] para personalmente hacer cumplir mis órdenes me hallo facultado para ello y mucho más por el Señor General del Perú Don Antonio de Álvarez de Arenales quien me ha hecho jefe de todas estas provincias con fecha 18 del mes pasado, desde el campamento de Postrer Valle, lo que le comunico a Vuestra Merced y a los demás que le acompańan. AGNA, sala VII, leg. 2568, doc. 1166. [negritas añadidas]

Como se observa, el nombramiento de Zárate provino directamente del comandante general de las fuerzas del interior, de la manera más formal posible, es decir, con despachos escritos. No era la primera vez que Álvarez de Arenales procedía de esa forma. En otra carta de 23 de diciembre del año antedicho, mediante José Bentura Zárate le concede el nombramiento de comandante a Santiago Fajardo: "Por los conocimientos militares y acreditada inteligencia de Don Santiago Fajardo, a más de la efectiva adhesión que le tiene esa gente será muy conveniente que lo hayan y reconozcan por Comandante para que mejor la dirija evitando de todos modos etiquetas de disensión y desobediencia” AGNA, sala VII, leg. 2565, doc. 437. [negritas ańadidas]

En ambos casos, se trata de gente que por una u otra razón resaltaron en el teatro de la guerra. Se sabe que José Ignacio Zárate fue natural de Pomabamba (hoy Azurduy). A principios de 1811, se fue a vivir a la ciudad de La Plata, donde actuó en representación de los vecinos de Pomabamba contra los abusos del alcalde del lugar. Más adelante, actuó bajo las 
órdenes de Manuel Ascencio Padilla en las tropas que este había conformado (Canedo Gutiérrez, 2016, pp. 457-459). El hecho de que se haya hecho cargo de la defensa de los vecinos de Pomabamba muestra la popularidad que tenía en su región, lo cual lo debió catapultar para ser reconocido por Álvarez de Arenales. Por otro lado, Fajardo era un personaje notable en Cochabamba antes del conflicto, pues era propietario de minas y haciendas en aquella región (Demélas, 2007), lo que unido a la "adhesión que le tiene la gente" le aseguraron un lugar en el esquema del comandante general del interior.

\section{Conformación social de la tropa de Álvarez de Arenales}

Como en la mayoría de los casos de la época, la gente con la que se nutrió la tropa de Juan Antonio Álvarez de Arenales era de todo tipo y estatus social. Sin embargo, existen detalles que no dejan de ser llamativos. Después de la derrota de Belgrano en Ayohuma en noviembre de 1813, este tuvo que retirarse hacia las Provincias Unidas del Río de La Plata. Arenales, al no poder sostenerse en la ciudad de Cochabamba ante la arremetida de las tropas realistas, tuvo que salir de esa región e internarse en los valles cruceños. Su salida debió ocurrir en lamentables condiciones, pues él mismo reporta que salió: “... con mi corta guarnición, y la gente decidida que quiso seguirme..." (AGNA, sala VII, leg. 2565, doc. 429). Su fuerza no superó los 200 hombres entre carabineros y fusileros, los que tomaron el nombre de "División de Cochabamba” (Quispe Escobar, 2018, p. 19).

Álvarez de Arenales tomó la decisión de aumentar sus fuerzas y que fueran, sobre todo, disciplinadas y por lo tanto competentes para la batalla: “... he hecho pie aquí disciplinando a la gente en diarios y activos ejercicios, dispuesto a rechazar a las partidas enemigas..." (AGNA, sala VII, leg. 2565, doc. 429), decía nuestro personaje. Sin 
embargo, se topó con una dura realidad: la falta de oficiales capaces y de resolución, de la misma forma, los soldados que conformaron sus tropas fueron una queja constante en sus oficios. En una carta fechada el 14 de febrero de 1814 , decía que:

Igualmente apunte que me seguía una tropa de decididos de todas clases, sobre cuya inutilidad me he desengañado demasiado, y por esto he determinado repartirlos en los pueblos de misiones, quedándome únicamente con lo que es tropa útil, obligando a algunos de aquellos de la inferior clase a que formalmente tomen las armas, pues los demás con el abusivo y perjudicial pretexto de ser decentes, nobles y caballeros, nada ayudan y mucho estorban, mayormente los que figurándose militares con las graduaciones de su arbitrariedad nada entienden menos de esta profesión... (AGNA, sala VII, leg. 2565, doc. 436).

La cita muestra una clara separación social imperante en tiempo de guerra. Aquellos que se consideraban "decentes, nobles y caballeros", pensaban que solo por ese hecho eran merecedores de rangos militares, aunque no tuvieran la más mínima idea de cómo encarar las batallas, lo que a la postre significaría la derrota. Es posible que muchos de aquellos a los cuales se refería en algún momento habrían formado parte de las milicias urbanas y rurales que se instalaron a consecuencia de los sucesos de 1781 y 1809 , pero también por la entrada en rigor del Reglamento de Milicias Disciplinadas de Infantería y Caballería del Virreinato de Buenos Aires, publicada en 1802. Esas milicias estaban bajo el mando de "lo más selecto y granado del patriciado local", como diría Juan Marchena (1992, pp. 107, 190) No está en las referencias bibliográficas. Eso puede ser el origen de la queja de Álvarez de Arenales, sin embargo, la suposición no puede ser concluyente al no tener más datos sobre aquellos que conformaron sus tropas.

Por otro lado, Álvarez de Arenales muestra mayor confianza en las clases inferiores, o sea, en los indígenas para confor- 
mar las tropas como soldados y obligaba a alguno de ellos a enlistarse en la tropa formal. Por ubicarse entre los valles cochabambinos y chuquisaqueños como en la selva y Chaco de Santa Cruz, tanto él como sus soldados tenían tratos con indígenas de origen quechua o aimara y con los chiriguanos o la "gente de arco y flecha", como se les ha identificado.

De esa forma, en la batalla de Samaipata, sucedida en agosto de $1814,{ }^{20}$ informó que: “... dos compañías, segunda y cuarta se componían de los naturales de misiones...". Si tomamos en cuenta que cada compañía se componía de 40 a 90 efectivos, hubo entre 80 y 180 indígenas que participaron en esa batalla como soldados. Lastimosamente, al parecer todavía no habían tenido el entrenamiento debido, pues una vez que la acción concluyó, no se habrían vuelto a reunir con su comandante y muchos habrían optado por irse a sus casas (AGNA, sala VII, leg. 2565, doc. 436).

Otro rostro de la participación indígena que Álvarez de Arenales conoció fue el del movimiento en masa. De esa forma, informaba a Rondeaú sobre un movimiento: "Los naturales de San Lucas, Puna, Bartolo, y sus inmediaciones emprendieron su revolución, mataron al subdelegado de Puna, Sermeño y cosa de 30 hombres de su escolta..." (AGNA, sala VII, leg. 2565, doc. 436). A raíz de ese hecho, desde Potosí se mandó una partida de 40 hombres armados a castigar a los indígenas, pero estos los esperaron en Bartolo, donde sufrieron el mismo destino del subdelegado y sus acompañantes. Se mandó entonces una tropa de 200 hombres veteranos más dos piezas de artillería en busca de los insurrectos.

20 Álvarez de Arenales culpaba a los malos informes de sus espías que le dijeron que las fuerzas del rey no pasaban de 200 soldados, cuando en verdad eran más de 400. Además, muchos de los oficiales a su mando no se comportaron de forma adecuada. AGNA, sala VII, leg. 2565, doc. 436 
En ese punto, se hizo presente la figura del comandante Ignacio Zarate, quien tomó el mando de los indígenas. Sin embargo, su presencia poco ayudó a los rebeldes, pues no pudieron hacer nada contra la fuerza de sus oponentes y tuvieron que escapar hacia Milacaya, donde intentaron hacer alguna resistencia. Nuevamente vencidos, huyeron hacia Turuchipa, cerca del río Pilcomayo: “... donde segunda vez por tan temeraria resistencia volvió a sufrir el último lastimoso destrozo..." (AGNA, sala VII, leg. 2565, doc. 429). Los pocos que sobrevivieron escaparon hacia Collpa. Álvarez de Arenales culpó de estos sucesos a Zárate, de quien no tenía buena opinión y lo culpó de una acción "temeraria" (AGNA, sala VII, leg. 2565, doc. 429).

A través de este relato, doy cuenta de que Álvarez de Arenales valoraba la presencia y la fuerza de los indígenas a los que calificó de: “... aquellos fieles y entusiasmados indígenas..." (AGNA, sala VII, leg. 2565, doc. 429), pero que, por causa de un mal comando, sufrieron una derrota con gran pérdida de vidas. Por lo tanto, nuevamente cuestionó la valía de aquellos que sin tener capacidad se atrevían a dirigir hombres en armas.

El valor y la importancia de los indígenas en la guerra se confirma en otro reporte de junio de 1815, cuando informó acerca del movimiento de tropas enemigas que se trasladaban de Challapata hacia Tapacarí, en su camino: “... han sido perseguidos tenazmente por los naturales de todos aquellos lugares y partidas sueltas que han estado a mi dirección las que me comunicaron ... que los enemigos se hallaban en Charapaya rodeados de cinco porciones numerosas de naturales, que los combatían con hondas y galgas muy empeñadas" (AGNA, sala VII, leg. 2565, doc. 429).

Existía otro grupo de "naturales" a los que Álvarez de Arenales les prestaba atención, estos se encontraban en la selva 
agreste o en el Chaco ardiente y constituían una fuerza temible por su ferocidad. ${ }^{21}$ Nuestro personaje habla de ellos y el apoyo que le prestaban, de esa forma cuando reporta acerca de sus movimientos en Vallegrande en febrero de 1814, indica: "... que aun cuando no consiga el auxilio de armas, y otros aprestos necesarios, creo que lo haré con las pocas mías y alguna gente de flecha que se me ofrece..." (AGNA, sala VII, leg. 2565, doc. 429) [negritas ańadidas].

Esta fuerza de combate, "de arco y flecha" habría estado en contacto con Álvarez de Arenales y también con Manuel Ascencio Padilla, quien fue muy cercano a Cumbay, el gran capitán chiriguano. Ignacio Warnes también habría tenido tratos con este personaje, pues antes de la batalla de la Florida reportaba que vendría con: “... cerca de mil hombres, entre fusileros, caballería de lanza y gente de flecha, con dos piezas de artillería..”, presentándose a la postre sólo con algunos “... pardos y morenos, un corto resto de fusileros mestizos y una compañía de naturales montados..." (AGNA, sala VII, leg. 2565, doc. 429).

¿Quiénes eran esta "gente de flecha"? y esos naturales montados ¿eran los mismos o se trataba de otro grupo de indígenas? Trataré de responder estas preguntas con la información que tengo disponible. El teniente coronel Diego de la Riva, desde Cabezas, en abril de 1814, en una

21 Desde la época de la conquista española hasta finales del siglo XIX, los diversos grupos chiriguanos, o más propiamente guaraníes, fueron un constante enemigo en la frontera del Chaco, pues cada cierto tiempo hacían sus incursiones a las haciendas que se asentaron en esos lugares. En la guerra de la Independencia en Charcas, uno de sus más famosos líderes, Cumbay, apoyó a Manuel Ascencio Padilla en sus correrías. También se entrevistó con José Manuel Belgrano en su ingreso a esa región, con lo que se afianzó una alianza entre estos grupos y los insurgentes (Saignes, 2007, pp. 121-122). 
carta remitida a nuestro personaje reporta que: "Me ha sido indispensable reforzar el destacamento del punto de Estacas con 25 fusileros a los 21 que tenían los del destacamento que componen 46, fuera de los 250 cambas que he despachado" (AGNA, sala VII, leg. 2565, doc. 727). Parece que surgió un nuevo grupo en ese escenario, sin embargo, en la misma carta más adelante dice: “... he tenido por conveniente tomar el vado de reforzar con la gente armada de fusilería y flecha que arriba refiero..." (AGNA, sala VII, leg. 2565, doc. 429). Entonces llego a la conclusión de que la gente de flecha eran los cambas. ${ }^{22}$ Pero, ¿quiénes exactamente eran estos cambas?

Para Thierry Saignes: “... la apelación de camba, parece restringirse a los chiriguanos aliados o cristianos”. Más adelante, ese mismo término se aplicó al mestizo campesino del oriente y luego por extensión a los pobladores de Santa Cruz (Saignes, 2007, p. 229). De esta forma, se puede concluir que la "gente de flecha” a la que Álvarez de Arenales, así como los demás comandantes de su división se referían, eran los chiriguanos.

La presencia de estos cambas o chiriguanos fue notable en tiempos de crisis por la falta de elementos de los cuales valerse. Andrés García Camba en sus memorias refiere el hecho de que fue gracias a que estos se unieron con Álvarez de Arenales que este pudo rehacerse después de su derrota en la acción de San Pedrillo a principios de febrero de 1814 (1916, p. 163). ${ }^{23}$

22 José Santos Vargas en su diario de guerra cuenta un rumor, el cual afirmaba que el comandante José Manuel Chinchilla volvería de Arcopongo con "... una tropa buena de 300 flecheros cambas (que son los indios bravos e infieles)" (Vargas [1852] 2016, p. 417). Esta cita confirma que la gente de flecha eran los cambas.

23 Luego de la acción de San Pedrillo: "Retirado Arenales a Santa Cruz de la Sierra con los dispersos que pudo reunir, y eficazmente auxiliado allí 
Por otro lado, se les utilizaba como apoyo en los destacamentos de vigilancia. En una nota del comandante José Manuel Zurita y Ríos, enviada en abril del año mencionado, este le remarca el hecho de que una tropa de 110 soldados y 25 cambas, a las órdenes de Apolinar Arenales estaban destacados cerca de San Pedrillo para cortar toda comunicación del enemigo (AGNA, sala VII, leg. 2567, doc. 739). Lo mismo ocurrió en el punto de Estacas cuando Diego de la Riva decidió reforzar la vigilancia de este punto con: “... la gente armada de fusilería y flecha..." nombrando para el caso como comandante de la partida a don José Gonzáles, para lo cual pidió la venía de Âlvarez de Arenales (AGNA, sala VII, leg. 2567, doc. 770.

Por otro lado, nuestro personaje se ocupó de conformar un cuerpo militar disciplinado capaz de sostener encuentros con el enemigo. Hasta ahora, no se ha encontrado el pie de fuerza completa al principio de su campaña en Vallegrande, aunque menciona le existencia de los mismos. ${ }^{24}$ Sin embargo, se ha consultado el listado de una compañía que se encontraba al mando del capitán Juan Vicente Pedraza, fechado en marzo de 1814. Ese cuerpo militar estuvo conformado por tres oficiales superiores (capitán, teniente y subteniente), diez oficiales subalternos (entre suboficiales, sargentos y cabos), dos tambores y 65 soldados, de los cuales ocho no poseían armas de fuego y 11 se encontraban hospitalizados con heridas graves y leves (AGNA, sala VII, leg. 2567, doc. 734).

por el gobernador Warnes y aun por los indios infieles del valle de Ingre, llamados chirihuanos, logró rehacerse más pronto de lo que se esperaba" (García Camba, 1916, p. 163).

24 Es posible que esos documentos se encuentren traspapelados en ese mismo fondo, por lo cual no aparecen de forma rápida, o en otro fondo diferente del Archivo General de la Nación Argentina. 
De la misma forma, en un estado de fuerza remitido a José de Rondeaú el 16 de junio de 1815, le hace conocer que su tropa estaba conformada por 38 oficiales distribuidos en siete compañías de infantería, uno de granaderos volantes, uno de artillería y uno de caballería, más 14 oficiales pertenecientes a la plana mayor (AGNA, sala VII, leg. 2565, doc. 435). De esa lista, solo uno de ellos puede asociarse al estamento indígena; se trata del abanderado Francisco Quirquincha. Los demás eran de ascendencia europea.

El hecho de que en esa lista de oficiales y soldados solo aparezca un apellido de origen indígena hace presumir que se habrían preferidos oficiales y soldados de origen criollo o a lo mucho mestizo. El caso de Quirquincha puede ser particular, sobre todo teniendo en cuenta que ese apellido está ligado a un viejo linaje cacical paceño, ${ }^{25}$ lo cual le habría dado la entrada al cuerpo de oficiales. Sin embargo, hay que tener en cuenta que ese estado de fuerza muestra la oficialidad, no así la tropa en la sí estaba presente el estamento indígena, como se vio en una parte anterior.

Un contraste con esa situación son las tropas y los oficiales subalternos de la División de los Valles de La Paz y Cochabamba, surgida poco después del retiro de Álvarez de Arenales de suelo charquino, bajo el mando de Eusebio Lira. En esa fuerza, existían varios sargentos y cabos de origen indígena. Algunos, como Rafael Copitas o Miguel Mamani, alcanzaron el rango de capitán y gran parte de las tropas 98 de soldados guerrilleros eran de ese origen (Vargas [1852] 2015). No puedo argumentar con certeza la preferencia de

25 Según el diccionario histórico-biográfico de Nicanor Aranzaes (1915, p. 622), Quirquincha fue uno de los caciques principales en la región del río Choqueyapu, donde se asentó la ciudad de La Paz al principio de la etapa colonial. Actualmente, su casa se encuentra en pie y es una de las construcciones más antiguas de la urbe paceña. 
Álvarez de Arenales por el nombramiento de oficiales criollos o mestizos. Quizá se haya debido a su preferencia o a alguna instrucción superior, pero hace falta comprobarlo.

Por otro lado, al principio de su campańa en Vallegrande tuvo que reclutar y entrenar a soldados de origen indígena por la falta de interés de los criollos, pues al parecer no consideraban ese empleo digno de ellos. Con el pasar del tiempo, nuestro personaje por fin logró que estos se incluyeran en las tropas como soldados, es lo que se podría deducir de las listas de las compañías encontradas. ${ }^{26}$

Con esas fuerzas, Álvarez de Arenales afrontó la guerra en Vallegrande y tuvo el gran éxito de la batalla de la Florida, en mayo de 1814, pero también grandes reveses, como la acción de Samaipata en agosto de ese mismo año. Por otro lado, supo hacer funcionar a sus tropas en conjunción con el sistema de divisiones organizado por él, lo que trataré en el siguiente acápite.

\section{De divisiones patrióticas y personajes}

Anteriormente, he abordado la organización del sistema de divisiones con base en las autoridades políticas y militares, como comandantes y capitanes. Queda un asunto por resolver, el funcionamiento de esa organización, que tenía como base a las divisiones patrióticas, bajo el comando de Juan Antonio Álvarez de Arenales.

La división al principio fue una unidad administrativa, que pasó a ser táctica gracias al desarrollo de las guerras napoleóni-

26 Este hecho me parece llamativo, pues ese silencio parece ocultar la presencia de indígenas entre las tropas regulares de Álvarez de Arenales. Quizás muchos hayan adoptado apellidos de origen español o simplemente no se los tomó en cuenta. 
cas en Europa: "Solían presentar las tres armas en su conjunto, con artillería y caballería agregadas a esta formación de combate". En el caso europeo, estaban dirigidas por un general de división (Sicilia Cardona, 2016, p. 54). Confirmando esta situación, en 1889, es decir, poco más de sesenta años de la fundación de Bolivia, el término "división" es entendido como: "La base fundamental para el estudio de la reunión de tropas de las tres armas" (Villalva [1889] 1928, p. 12). Se refiere a las tres armas del ejército de tierra, que son la infantería, la caballería y la artillería. La reunión de estas daría lugar a la división militar, un grupo compacto y autónomo en sus acciones.

En ese caso, una "división patriótica" estaba compuesta por la reunión organizada de la tropa, con mandos establecidos desde el comandante hasta el último soldado. Esa fuerza contaba con infantería y caballería principalmente, sin embargo, la artillería, o sea, la presencia de cañones no se descuidaba y se procuraba por todos los medios posibles. ${ }^{27}$

No es difícil suponer que ese tipo de organización pasó a América con los oficiales ilustrados que llegaron antes del comienzo de la guerra de la Independencia, es el caso de Joaquín de la Pezuela ${ }^{28}$ o el mismo Juan Antonio Álvarez de

27 Un claro ejemplo es la presencia de dos cañones en la división de Álvarez de Arenales cuando sucedió la batalla de la Florida (Paz, 1919). Por otro lado, la División de los Valles de La Paz y Cochabamba al mando de Eusebio Lira en 1817 contaba con un cañón (Mamani Siñani, 2010).

28 Joaquín de la Pezuela se había formado como ingeniero militar en Segovia. Llegó al Perú en 1805, enviado desde España para construir una fábrica de pólvora. Ya en ese Virreinato, se desempeñó como subinspector de artillería. Fue designado como general en jefe del Ejército del Alto Perú en 1813 en reemplazo de José Manuel Goyeneche. En todas sus batallas dio especial importancia a la utilización de la artillería. Esto se puede comprobar en su relato de la batalla de Ayohuma, pero en especial en la de Viloma o Sipe (Pezuela, 2020, pp. 11, 26, 44, 143). 
Arenales. Por las ventajas que se obtenía, al ser cuerpos limitados y de gran movilidad, su conformación fue popular tanto entre los insurgentes como los realistas, con la diferencia de que en Charcas estaban al mando de coroneles o tenientes coroneles, que al mismo tiempo podían tener nombramientos político-administrativos.

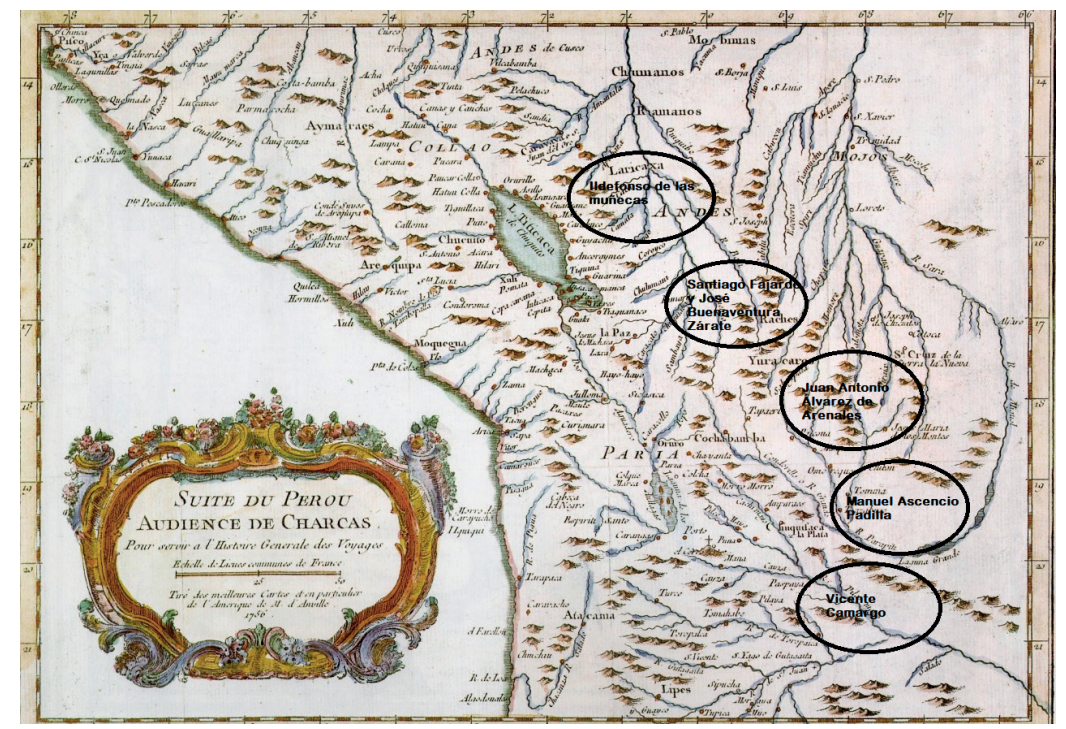

Mapa 1. Ubicación aproximada de las divisiones patrióticas que conformaban el sistema de guerrillas. (Suite Du Pérou. Audience de Charcas, 1776).

El sistema de divisiones en guerrilla operaba de la siguiente manera. Al sur, estaba la división de Vicente Camargo que tenía el cargo de subdelegado de Chayanta cuando ingresó el ejército auxiliar al mando de José de Rondeaú, pero su dominio cotidiano fue la región de Cinti. A su lado, operaba la división de Manuel Ascencio Padilla, que tenía el cargo de subdelegado de las fronteras de Tomina y Pomabamba, siendo este su territorio (AHCDL, C-12.15, No 214, f. 4-4v. (Torres, 2015, p. 103). Colindando con esta, en el partido de 
Valle Grande se encontraba la división de Juan Antonio Álvarez de Arenales, comandante general de las tropas del interior. Esa tropa fue conocida como la división de Cochabamba, aunque operaba en Vallegrande y se enlazaba, mediante su vanguardia, con las tropas dirigidas por Santiago Fajardo y José Bentura Zárate. Esas, a su vez, servían de enlace con la división de Juan Manuel Pinelo cuando este se encontraba en La Paz y luego con la división de Ildefonso de las Muñecas en Larecaja. De esa forma, se completaba el círculo de dominio de los territorios liberados.

Tanto Joaquín de la Pezuela como Jerónimo Valdés dan cuenta en sus escritos de que las posiciones que habían tomado los insurgentes formaban un corredor extenso por el cual las comunicaciones fluían y al mismo tiempo eran posiciones estratégicas para ataques por el flanco y la retaguardia del ejército realista (Pezuela, 2020, p. 155; Valdés, 1895, p. 167). Es por eso que envió repetidas expediciones para tratar de acabar con la resistencia de las divisiones insurgentes. ${ }^{29} \mathrm{Se}$ debe recalcar el hecho de que esas fuerzas estaban bajo el comando de Juan Antonio Álvarez de Arenales. Esto se puede observar en un informe que Rondeau le envía al director de estado de las Provincias Unidas del Río de La Plata:

Tengo la satisfacción de remitir a las superiores manos de vuestra excelencia... las adjuntas copias certificadas de los primeros partes oficiales que he recibido de los comandantes don Vicente Camargo y don José Mateo Berdeja... Se hallan aquellos a la cabeza de una de las Divisiones del interior que bajo la dirección del

29 Una de esas expediciones fue la del teniente coronel José Joaquín Blanco, quien el 25 de mayo de 1814 se enfrentó a Álvarez de Arenales y Warnes en la batalla de la Florida. En aquella ocasión, se celebró una victoria insurgente, lo que posibilitó que las fuerzas de José Rondeau pudieran entrar en territorio charquino y avanzar hasta territorio cochabambino, donde finalmente fue derrotado (Paz, 1919). 


\section{benemérito coronel don Juan Antonio Álvarez de Arenales se} han empleado con constancia heroica en hostilizar al enemigo por su retaguardia y flancos. (Biblioteca de Mayo. Colección de Obras y Documentos para la Historia Argentina, t. XV Guerra de la Independencia, p. 13352). [negritas añadidas]

Camargo y Berdeja estaban a la cabeza de una división, bajo las órdenes de Juan Antonio Álvarez de Arenales. Sobre esa base, se puede decir que el funcionamiento del sistema de divisiones se sustentaba en las divisiones militares acantonadas en un espacio territorial definido, que actuaban con la táctica de la guerra de guerrillas y respondían a la autoridad y comando de Juan Antonio Álvarez de Arenales como comandante en jefe de las tropas del interior.

Por su lado, Vicente Camargo empezó operando en la zona de Santa Elena, pues fue nombrado comandante de esa zona por Manuel Ascencio Padilla (ABNB, Rück 304, f 10v, Torres 2015, p. 52. Sin embargo, se asentó en la zona de Cinti, más o menos donde estaba el comando de José Ignacio Zárate, lo que provocó cierto disgusto a este. Líneas arriba vimos que este último intentó colocar bajo su mando a Camargo, lo cual fue reportado a Álvarez de Arenales, quien lo favorecía. Ante esa situación, Zárate no tuvo otra opción que quejarse ante Ignacio Warnes, pues en una carta del 5 de septiembre de 1814 le dice que: "Don Vicente Camargo estaba por Umańa nombrado comandante para estos lados y es más de haber andado libero en su nombramiento dicho Umaña porque no debía hacerlo yo no necesito a tales acompańados..." (AGNA. sala VII, leg. 2568, doc. 1192), finalmente le dice que lo va a desarmar.

En vista de lo mencionado en un anterior acápite, Umaña estaba bajo la tuición de Güemes por estar en suelo tarijeño, al avanzar este al norte y tomar contacto con Manuel Ascencio Padilla (Ramallo, 1975), inmediatamente este dependía de las órdenes de la máxima autoridad en este territorio, que era 
Juan Antonio Álvarez de Arenales. En ese sentido, es correcta la apreciación de Zárate al oponerse al nombramiento de Camargo como comandante puesto por Umaña.

Esta situación fue corregida el 29 de octubre de 1814, pues Vicente Camargo le envió una carta a Álvarez de Arenales en la que le dice: "Tengo el honor de besarle a Vuestra Merced sus manos y que me reconozca por uno de sus más ínfimos soldados, mucho tiempo hace que había deseado merecer este honor más la suerte no me ha proporcionado coyuntura, pero ahora que nuestro superior jefe me ha abierto margen que necesitaba..." (AGNA, sala VII, leg. 2568, doc. 1167).

De esa forma, Camargo se puso a disposición de Juan Antonio Álvarez de Arenales, por órdenes de los "jefes superiores". Es sintomático el hecho de que esa declaración se hiciera un día antes de la salida de la instrucción que designa al Gobernador Militar y Político de Cochabamba como comandante general de las tropas del interior. Ante esa situación, solo queda suponer, hasta que se demuestre lo contrario, que Camargo recibió pliegos desde Buenos Aires en los que ordenaban colocarse bajo la sujeción de Álvarez de Arenales.

El caso de Manuel Ascencio Padilla es un poco más claro, hay datos tempranos de 1810 en los que se presenta ante Castelli en Sapiri (Querejazu, 2005, p. 12). Luego de la derrota de Guaqui, fue perseguido por las autoridades realistas y tuvo 104 que huir hacia las provincias del sur. Allí se encontró en las batallas de Tucumán y Salta. Ingresó con Belgrano al territorio de Charcas y luego que este fue derrotado en Ayohuma y Vilcapugio, Padilla se retiró hacia el distrito de La Laguna (Paz, 1919, p. 346).

Padilla en primera instancia recibió el título de comandante de las doctrinas de Moromoro, Pitantora, Guaicoma, Poc- 
po, Quilaquila, Punilla y sus contornos por parte de Esteban Arze luego de la derrota de Guaqui. Una vez emigrado a suelo Salteño, Belgrano le confirmó el título de comandante de los pueblos (Querejazu, 2005, pp. 13, 19). En abril de 1814, Padilla le hizo recordar su nombramiento a los soldados de Umaña que venían a arrestarlo, pues: "Él rechazó la orden e hizo presente que era comandante de esas provincias con títulos expedidos por la suprema junta de Buenos Aires" (Ramallo, 1975, p. 71).

En julio de 1815, Padilla fue reconocido como "teniente coronel y gobernador, subdelegado de estas fronteras de Tomina y Pomabamba" (AHCDL, C-12.15, No 214, f. 4-4v (Torres, 2015, p. 103 No está en las referencias bibliográficas), es decir, cuando José de Rondeaú estaba presente en Charcas. Manuel Belgrano, una vez que se hizo cargo nuevamente del Ejército del Norte de las Provincias Unidas, desde Tucumán le expidió el nombramiento de "Coronel de Milicias Nacionales" el 23 de octubre de 1816 (Trelles, 1872, pp. 183-184, citado en Torres, 2015, p. 130 No está en las referencias bibliográficas).

Está claro que Padilla se refiere al título de comandante de los pueblos, pero además de este, tanto Álvarez de Arenales como las autoridades del ejército de auxiliar se referían a él como "Subdelegado Militar del Partido de Tomina". ${ }^{30}$ No se sabe si ese nombramiento le fue conferido por los jefes superiores o por el comandante general de las fuerzas del interior, lo que es indudable es que Padilla tenía la aquiescencia de Buenos Aires, ahora, ¿reconocía este la autoridad de Álvarez de Arenales? Todo parece apuntar a que la respuesta es afirmativa.

En una carta del 18 de febrero de 1815, el comandante en jefe de las tropas del interior le dice a Padilla que: "Es indispensa-

30 Carta de Martín Rodríguez a Manuel Ascencio Padilla (Ramallo, 1975). 
ble que usted tenga a la vista siempre todas mis prevenciones e instrucciones y se arregle a ellas puntualmente, pues de lo contrario no nos entenderemos y la responsabilidad será terrible" (AGNA, sala VII, leg. 2565, letra K, doc. 437). Lo que le dice es tanto una orden como una advertencia, no de reprimenda, sino de un futuro fracaso en caso de no estar combinados.

En los hechos, la reunión y las operaciones de ambas divisiones se realizaban sin mayor dificultad. Quizá la muestra más clara sea la toma de Chuquisaca, pues la combinación para ese fin estuvo muy bien elaborada. Primero, Padilla avanzó hacia esa ciudad y al mismo tiempo Zárate hacía lo propio sobre Potosí, lo cual distrajo a la fuerza de Pezuela que envió a 400 hombres a socorrer esa villa y dejó desprotegida la sede de la audiencia. Por otro lado, Camargo se aproximaba hacia Cotagaita, uno de los cuarteles generales de las tropas del rey, para terminar, Rondeaú avanzaba desde el sur. Todos esos movimientos hicieron que Pezuela retrocediese hacia Condo en Oruro. De esa forma, Álvarez de Arenales y Padilla se vieron libres para ocupar Chuquisaca el 27 de abril de 1815 (Crespo, 1978, p. 400).

Esa coordinación se puede verificar en el informe que Álvarez de Arenales le dirigió a Rondeaú el mismo día de la toma de Chuquisaca:

... tuve indispensable el movimiento que verifiqué el día veintiséis de marzo próximo pasado del valle Grande al partido de $\mathrm{La}$ Laguna con el designio de amparar y proteger las armas, y división que tuve encargadas al comando del Subdelegado Don Manuel Ascencio Padilla... pude lograr mi reunión, arreglo y organización de las divisiones, que en importancia correspondía en número de trecientos setenta hombres armados con alguna caballería del país y naturales patriotas. Componer muchas armas de la División subalterna que se hallaban inutilizadas y prepararme para toda operación defensiva u ofensiva hasta el 23 del dicho mes, que con determinación de batir y tomar esta plaza me puse 
en marcha hacia ella. (Biblioteca de Mayo, Colección de Obras y Documentos para la Historia Argentina. t. XV: Guerra de la Independencia, p. 13447). [negritas ańadidas].

De ese extracto se desprenden tres cuestiones importantes. Primero, Álvarez de Arenales se movió de Valle Grande a la Laguna en auxilio de Manuel Ascencio Padilla. Segundo, este último estuvo a cargo de una "división" que le fue encargada por el comandante general de las provincias interiores, es decir, estaría bajo su comando. Y tercero, esta estaría considerada como una "división subalterna", pues la principal es la que estaría bajo el comando directo de Álvarez de Arenales.

Esas divisiones estaban diseminadas en todo el territorio del dominio de Juan Antonio Álvarez de Arenales, es decir, desde Cinti hasta La Paz, como se especifica en la instrucción de José de Rondeaú: “... pero a pesar de ello las Divisiones Patrióticas de los varios lugares que cubrían los puntos de la comunicación bajo mi dirección han conseguido muchos y muy considerables triunfos contra la erguidad de los tiranos..." (AGNA, sala VII, leg. 2565, doc. 437) le dice el comandante general del interior a José Bentura Zárate en una carta de 11 de marzo de 1815.

Ahora, tanto José Bentura Zárate, ${ }^{31}$ que tenía el rango de teniente coronel, como Santiago Fajardo, eran los comandantes de la zona de Ayopaya; el primero tenía su cuartel en la hacienda de Guallipaya, que era de su propiedad y se encontraba a media legua del pueblo de Machaca (Vargas [1852] 1982). Este último lugar se encuentra en medio de las poblaciones de Palca, hoy Independencia, capital de la

31 Estos dos personajes se encuentran en el diario de José Santos Vargas, pero al primero se le conoce como José Buenaventura Zárate; sin embargo, en los documentos de Álvarez de Arenales aparece siempre como José Bentura Zárate, quizá esto se deba a un acortamiento del nombre, pero se trata del mismo personaje. 
provincia de Ayopaya, Cavari y Mohoza, en lo que hoy es el departamento de La Paz.

Sin duda, esa ubicación fue estratégica, pues sirvió de enlace entre la división de Juan Antonio Álvarez de Arenales, acantonada en Valle Grande, con el ejército venido desde el Cuzco al mando de Juan Manuel Pinelo y Torre, que tomó la ciudad de La Paz en septiembre de 1814. Sin embargo, el contacto entre los insurgentes del Cusco y las autoridades de Buenos Aires estuvo presente mucho antes de ese movimiento de tropas.

Andrés García Camba en sus memorias refiere que: "Según los mejores datos reunidos en el Gobierno superior del Perú, el plan de revolucionar el país fue trazado por los independientes en Salta, de acuerdo con varios de los oficiales capitulados y juramentados, y comunicado a sus partidarios ocultos y agentes de las provincias" (1916, p. 177). Esto hace pensar en un movimiento coordinado con el objetivo de que Pezuela dividiera sus tropas y así facilitar el ingreso de las fuerzas de Rondeau en Charcas. Lo que a la postre sucedió.

Pinelo, ni bien cruzó el Desaguadero, se contactó con Juan Antonio Álvarez de Arenales a través de una carta del 15 de septiembre de 1814. En ella, le pide que: “... a marcha redoblada, nos reunamos, y se proceda contra el tirano Pezuela" (Biblioteca de Mayo, Colección de Obras y Documentos para la Historia Argentina, t. XV Guerra de la Independencia, pp. 13383-13384). En ese documento, el comandante

108 cuzqueño se dirige al gobernador de Cochabamba como "Comandante en Jefe", lo cual, como se ha visto, se formalizó el 10 de octubre del ańo mencionado, por lo que se puede ver que Álvarez de Arenales ya actuaba como el máximo líder militar aun antes de su nombramiento formal.

Las fuerzas cuzqueñas se mantuvieron en La Paz hasta noviembre de 1814, cuando luego de las derrotas de Chacal- 
taya y Achocalla tuvieron que separarse en dos grupos, uno al mando de Pinelo, que regreso al Desaguadero, donde fue derrotado por las fuerzas realistas. El otro grupo se quedó con Ildefonso de las Muñecas, que se encontraba en el ejército del norte como capellán; esa tropa se dirigió a los Yungas y de allí a Larecaja, donde organizó su guerrilla (Aparicio Vega, 2001, p. 182).

Pinelo siguió enviando mensajeros a Álvarez de Arenales para que lo auxiliase. En diciembre de 1814, el padre Coxo se presentó en Cochabamba en búsqueda de las tropas insurgentes, fue tomado preso por las tropas realistas, pero luego le soltaron y se presentó ante Francisco del Carpio, quien informó que:

“... habiendo venido de emisario del Sr. Pinelo... expreso no haber tiempo ha tomado aquel la plaza de Cochabamba por sola la consideración de retirarse del importante punto del Desaguadero pues de verificarlo era evidente se le daba salida al enemigo que un poco más de paciencia de la nuestra debemos estorbarla”. (AGNA, sala VII, leg 2567, doc. 865).

Las cartas para Pinelo llegaron con prontitud, se enviaron varios mensajeros, que debieron pasar antes por el territorio de Ayopaya, sin embargo, el clima cambiante de la guerra hacía que muchas veces no llegaran a tiempo. El 29 de enero de 1815 Jacinto Garavito se quejó de que José Bentura Zárate no lo dejó pasar con los pliegos dirigidos al comandante cuzqueńo, argumentando que este ya no se encontraba en Desaguadero por haber sido derrotado por Ramírez y que la situación era demasiado peligrosa; informó también que: "otros anteriores que también se hallan detenidos en aquel punto” (AGNA, sala VII, leg. 2567,doc. 933).

La respuesta de Bentura Zárate ante esta queja no se dejó esperar, al día siguiente, le informó a Álvarez de Arenales so- 
bre las "ocurrencias de La Paz" (AGNA, sala VII, leg. 2565, doc. 437), en donde al final se indica que Pinelo pasó hacia el Cuzco, pero tenía el conocimiento de que el comandante Angulo se encontraba en Puno, por lo cual decidió mandarle los pliegos a ese señor (AGNA, sala VII, leg. 2567, doc. 934). Tardíamente, en marzo de 1815, Zárate comunicó que: “... el paquete dirigido al Comandante Pinelo a un mes que lo despaché a su destino" (AGNA, sala VII, leg. 2567, doc. 937), esto quiere decir que lo envió en febrero.

Sin embargo, la comandancia había pasado de Pinelo hacia Ildefonso de las Muñecas, quien según el reporte de Buenaventura Zárate fue quien dirigió la acción de Chacaltaya:

“... pues dos descargas de fusil de la vanguardia enemiga fueron suficientes para la total dispersión de la División de Pinelo; este jefe estaba todo el rato del fuego lleno de turbación, y los únicos que daban órdenes eran el Capitán Muñecas y el Mayor General Don Francisco Helguero...”. (AGNA, sala VII, leg. 2565, doc. 437) [negritas añadidas].

En la anterior cita, vemos nuevamente el uso del término 'división', lo cual confirma que la organización militar que se impuso en tiempos de la guerra de la Independencia fue de ese tipo. Luego de esa acción, Muñecas se habría retirado a Larecaja y desde allí envió partes y cartas al comandante en jefe de las tropas del interior, así lo reportaban las máximas autoridades de Buenos Aires:

“... ha llegado a manos del gobierno un oficio pasado por el doctor don Ildefonso de las Muñecas, comandante de las tropas independientes del interior, al coronel del regimiento № 12 , don Juan Antonio Álvarez de Arenales, desde su cuartel de Ayata con fecha 31 de agosto, [de 1815] en el que manifiesta haber circulado a los pueblos de Puno, Arequipa y Cuzco los papeles remitidos por el General de dicho ejército...”. (Paz, 1919, p. 344).

A través de esa nota, se verifica que Muñecas también estaba en contacto con Álvarez de Arenales y que este le enRevista del Instituto Riva-Agüero 
viaba diferentes papeles para su circulación en el Perú. Aún no tenemos la constancia, pero es muy probable que el cura comandante reconociera como su inmediato superior al comandante en jefe de las tropas del interior y en ese entonces coronel del Regimiento N.o 12.

El sistema de divisiones en guerrilla operó de manera eficaz contra las tropas del rey al mando del general Pezuela, lo que posibilitó la entrada con relativa facilidad del tercer ejército auxiliar al mando de José de Rondeaú. Por otro lado, las divisiones insurgentes se apoderaron de ciudades como Chuquisaca y Cochabamba, además de facilitar su estancia; sin embargo, esto no fue aprovechado por las huestes auxiliares.

Incluso después de la salida de Juan Antonio Álvarez de Arenales de tierras charquinas, el sistema que había organizado se mantuvo vigente con Manuel Ascencio Padilla a la cabeza. Una vez que este murió, las autoridades de Buenos Aires quisieron suplirlo con el nombramiento del teniente coronel Antonio Asebey; sin embargo, este no pudo mantener el orden y el sistema de divisiones despareció.

\section{Conclusiones}

En este trabajo, he descrito cómo las primeras concepciones del movimiento insurgente que aparecieron en el territorio de la antigua Audiencia de Charcas, conocido con el arcaico nombre de republiquetas, fue popularizado sin mucha reflexión al respecto. Sin embargo, surgieron voces que se opusieron a su uso y propusieron una alternativa para su estudio y conocimiento.

Esa propuesta pasó por la existencia de un sistema de divisiones al mando de Juan Antonio Álvarez de Arenales. Se ha señalado que estaba organizado en dos componentes primordiales. El primero, lo conformó la organización administrativa basada en subdelegados y alcaldes que organizó Manuel 
Belgrano y luego Juan Antonio Álvarez, quien pasó de ser el gobernador intendente de Cochabamba a comandante general de las tropas del interior.

La organización militar se basó en la existencia y nombramiento de comandantes o capitanes en distintos puntos de la región, quienes le debían obediencia a Álvarez de Arenales. Tanto subdelegados como comandantes estaban al mando de divisiones militares, con los cuales se armó el sistema de divisiones en un territorio continuo de zonas liberadas.

La división de Vicente Camargo operaba al sur de Charcas, luego estaba la división de Manuel Ascencio Padilla, continuaba la división que estaba al mando de las demás a la cabeza de Juan Antonio Álvarez de Arenales en Valle Grande. Luego estaban las tropas de los comandantes José Bentura Zárate y Santiago Fajardo, que servían de contacto con la división de José Manuel Pinelo y Torre, en primera instancia y luego con las de Ildefonso de las Muñecas, ubicada en la zona de Larecaja en La Paz.

Esas divisiones, como se conoce, actuaron generalmente con la táctica de la guerra de guerrillas, es decir, no buscaban el enfrentamiento con las fuerzas del enemigo, sino que las acosaban ya sea por la vanguardia, los flancos o la retaguardia para luego escapar. Esto no impedía que según el concepto de división como un cuerpo compacto, conformado por la

112 infantería, caballería y artillería, buscaran un enfrentamiento al estilo clásico, como en la batalla de la Florida. Por ello, a este tipo de organización se le debería conocer con más propiedad como sistema de divisiones en guerrillas.

Finalmente, se debe recalcar que este es el trabajo inicial de uno más profundo que se pretende realizar sobre la organización de ese sistema de divisiones en guerrilla, por lo cual con- 
sidero que las conclusiones aquí vertidas son las primeras que se alcanzan y espero profundizar más en el tema propuesto.

Recibido: 18 de octubre del 2020

Aprobado: 20 de abril del 2021

\section{Archivos consultados}

Archivo General de la Nación Argentina (AGNA), Colección General Juan Antonio Álvarez de Arenales.

\section{Referencias bibliográficas}

Aparicio Vega, M. J.

(2001) El clero patriota en 1814. Cusco: Municipalidad del Cusco.

Argentina. Senado de la Nación

(1963) Biblioteca de Mayo. Colección de Obras y Documentos para la Historia Argentina. Tomo XV Guerra de la Independencia. Buenos Aires.

Arguedas, A.

(1922) Historia general de Bolivia. El proceso de la nacionalidad: 1809-1921. La Paz: Escuela tipográfica del Colegio Don Bosco.

Arnade, C. W.

(2004) La dramática insurgencia de Bolivia (10ª ed.) La Paz: Editorial Juventud.

Bidondo A., E.

(1989) Alto Perú. Insurrección, libertad, independencia. La Paz: Ed. Artes Gráficas Rivolin Hermanos.

Canedo Gutiérrez, $\mathrm{H}$.

(2016) La guerra de las independencia en las Intendencias de Chuquisaca y Potosi. Sucre: Casa de la Libertad-Fundación Cultural del Banco Central de Bolivia. 
Cortés, M. J.

(1861) Ensayo sobre la historia de Bolivia. La Paz: Imp. de Beeche.

Costa de la Torre, A.

(2009) Ildefonso de las Muñecas y los mártires de la republiqueta de Larecaja (2a. ed.). La Paz: Gobierno Municipal de La Paz.

Crespo, L. S.

(1928) Vida y hechos notables del general José Miguel García Lanza y la influencia que ha tenido este héroe en los destinos de Bolivia. La Paz: Escuela Tipográfica Salesiana.

Crespo Rodas, A.

(1978) El ejército de San Martín y las guerrillas del Alto Perú. Separata del Primer Congreso Internacional Sanmartiniano. Buenos Aires.

Demélas, M. D.

(2007) Nacimiento de la guerra de guerrilla. El diario de José Santos Vargas (1814-1825). La Paz: Plural Eds., IFEA.

Díaz A., J.

(1943) Fastos militares de Bolivia. La Paz: Ejército de Bolivia. Biblioteca del Ministerio de Defensa Nacional.

Dipasquale, $M$

(2009) La gestión de Álvarez de Arenales. Presencia del rivadianismo en Salta (1824-1827). Revista Complutense de Historia de América, 35, 209-23.

El Rey

(1782) Real Ordenanza para el establecimiento e instrucción de intendentes de ejército y provincia en el Virreinato de Buenos Aires. Madrid: Imprenta Real 
España. Constitución

(1812) Constitución política de la monarquía española promulgada en Cádiz a 19 de marzo de 1812.

Finot, E.

(1946) Nueva historia de Bolivia: Ensayo de interpretación sociológica. Buenos Aires: Fundación Universitaria Patiño.

Gandarilla Guardia, N.

(2017) Warnes y Arenales en el Ejército Cruceño. Santa Cruz de la Sierra: El País.

García Camba, A.

(1916) Memorias del general Garcia Camba para la historia de las armas españolas en el Perú, 1809-1821.

Gil Montero, R.

(2007) Las republiquetas en la guerra de Independencia. Revista Andina (45).

Husson, P.

(1992) De la guerra a la rebelión. Huanta, siglo XIX. Cuzco: Centro de Estudios Regionales Bartolomé de las Casas, IFEA.

Lorandi, A. M.

(2016) Soberanías en pugna: Trayectoria andina del General Álvarez de Arenales. Historia y Cultura (28), 147-181.

Mamani Siñani, R. L.

(2010) La División de los Valles. Estructura militar, social y étnica de la guerrilla de La Paz y Cochabamba 18141817. La Paz: IEB-ASDI.

Mata, S.

(2000) Tierra en armas. Salta en la revolución. En Persistencias y cambios: Salta y el noroeste argentino, 17701840. Rosario: Prohistoria. 
Méndez, C.

(2014) La república plebeya. Huanta, formación del Estado peruano, 1820-1850. Lima: Instituto de Estudios Peruanos.

Mitre, B.

(1887) Historia de Belgrano y la guerra de Independencia de Argentina. Buenos Aires: Ed. Félix Lajouane.

Moreno, G. R.

(1997) Últimos días coloniales en el Alto Perú (10ª Ed.). La Paz: Juventud.

Paz, L.

(1919) Historia general del Alto Perú hoy Bolivia. Guerra de la Independencia (t. II). Sucre: Imp. Bolívar.

Pezuela, J. de la

(2020) Compendio de los sucesos ocurridos en el ejército del Perú y sus provincias (1813-1816). Ed. y prólogo de Pablo Ortemberg y Natalia Sobrevilla Perea. Lima: Biblioteca Bicentenario del Perú.

Querejazu, J.

(2005) La amazona y el caudillo. Sucre: Imp. Ed. Tupak Katari.

Quispe Escobar, A.

(2018) Tiempos de insurgencia. Guerra, politica y vida cotidiana en Cochabamba (1813-1819). Santa Cruz de la Sierra: El País.

Ramallo, M.

Batallas de la guerra de la independencia altoperuana. La Paz: Intendencia de Guerra.

Ramallo, M.

Guerrilleros de la independencia. Los esposos Padilla. La Paz: Gonzales y Medina Imp. 
Ramallo, M.

(1975) Guerrilleros de la independencia. La Paz: S.E.

Real Ordenanza para el establecimiento e instrucción de intendentes de ejército y provincia en el Virreinato de Buenos Aires, 1782. Madrid: Imp. Real.

Roca, J. L.

(2007) Ni con Lima ni con Buenos Aires. La formación de un Estado nacional en Charcas. La Paz: Plural Editores, IFEA.

Sánchez Cari, A.

(2018) El movimiento insurreccional de Tarija durante el proceso de la independencia (1810-1825). Tesis para optar al grado de Licenciatura en Historia por la Universidad Mayor de San Andrés.

Sicilia Cardona, E.

(2016) Napoleón y revolución. Las guerras revolucionarias. Madrid: Nowtilus.

Soux, M. L,

(2010) El complejo proceso hacia la independencia de Charcas (1808-1826). Guerra, ciudadania, conflictos politicos locales y participación indígena en Oruro. La Paz: ASDI, IFEA, Plural-IEB.

Soux, M. L,

(2008) De la sublevación indígena a las guerrillas de Charcas. En A. Martínez y M. Chust (Eds.), Una independencia, muchos caminos: El caso de Bolivia (1808-1826). Castelló de la Plana: Universitat Jaume I.

Torres, B. N.

Vizente Camargo. El héroe de Cinti. Sucre: Ciencia Editores 
Urquidi, J. M.

(1967) Bolivianas ilustres: Las guerrilleras de la independencia. La Paz: José Camarlinghi Ed.

Valdés, J.

(1895) Documentos para la historia de la guerra separatista del Perú (t. II). Madrid: Imprenta de la Viuda de M. Minuesa de los Ríos.

Valencia Vega, A.

(1962) El indio en la independencia. La Paz: Talleres de la Imp. El Progreso.

Vargas, J. S.

([1852] 1982). Diario de un comandante de la independencia americana. 1814-1825. Transcripción, introducción e índices de Gunnar Mendoza L. México: Siglo XXI.

Villalba J.

(1928) Tácticas de las tres armas (ingenieros, aviación, carros de combate, gases) (10a. ed.) Madrid: Imp. del Asilo de H. del S. C. de Jesús. 


\section{Anexo \\ Diagrama de la División de Cochabamba.}

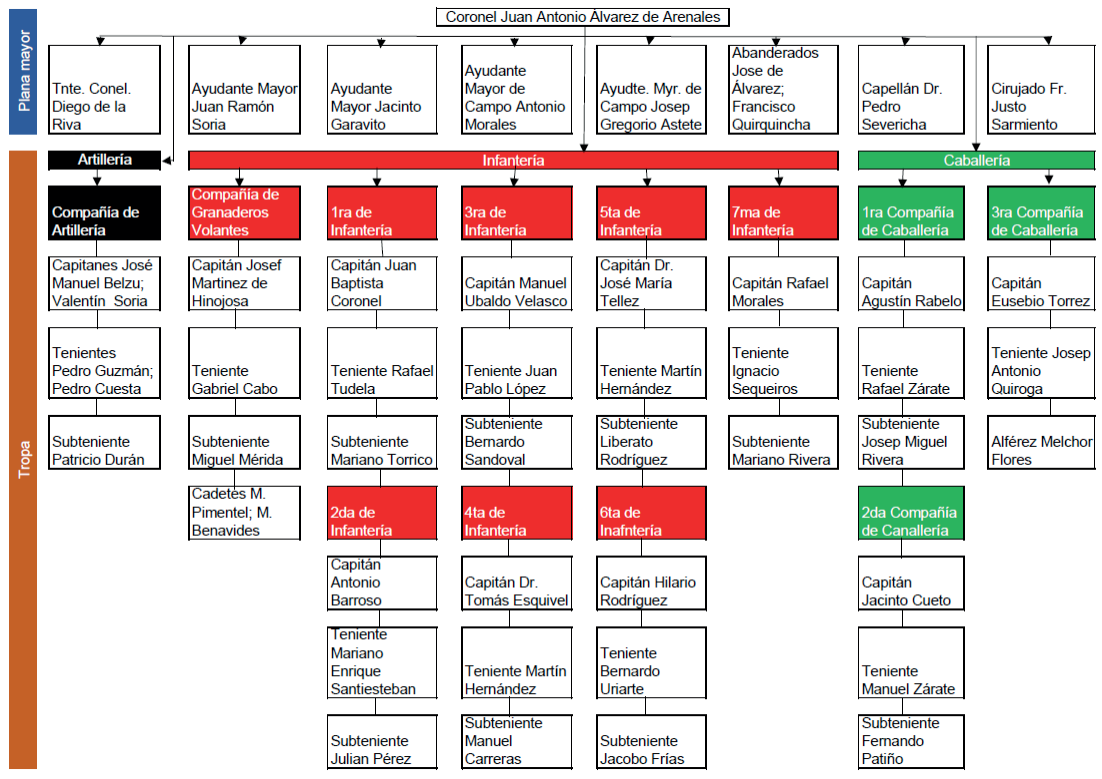

(Fuente: Archivo General de la Nación Argentina, Colección Juan Antonio Álvarez de Arenales) 